\title{
Monitoramento do Plano de Desenvolvimento da Educação: proposta de aprimoramento do Ideb e de painel de indicadores*
}

L eonardo Milhomem de Rezende e Paulo de Martino Jannuzzi

\section{Introdução}

A qualidade da educação básica parece ter entrado na agenda formal das políticas públicas do Estado brasileiro no ano 2000, depois de muito tempo debatida em círculos acadêmicos e políticos mais restritos. Até então, a pauta educacional dessa agenda estava claramente focada na necessidade de promover o ingresso massivo das crianças nas escolas do ensino fundamental, nas áreas mais pobres do País e, subsidiariamente, na melhoria do desempenho escolar dos alunos. Tendo logrado nos últimos 15 anos (1992 a 2006) o aumento significativo das taxas de cobertura no ensino fundamental, de 82\% para 96\% entre crianças e jovens de 7 a 14 anos, o esforço governamental (em nível federal e nos estados) concentra-se agora na busca de soluções para reverter 0 quadro pouco alentador revelado pelas avaliações sistemáticas de proficiência dos estudantes ao longo do ciclo escolar. 
Um fato revelador dessa preocupação com a qualidade de ensino foi a proposição, pelo Ministério da Educação (MEC), no âmbito do Plano de D esenvolvimento da Educação (PDE), de uma medida concreta e objetiva para monitoramento e avaliação dos resultados das ações e programas voltados a essa dimensão educacional: o Índice de D esenvolvimento da Educação Básica (Ideb). 0 D ecreto n 6.094/ 2007, que dispõe sobre o Plano de Metas Compromisso Todos pela Educação, legitima o Ideb como instrumento de avaliação da qualidade educacional, medido pela proficiência dos alunos nos exames padronizados, como o Saeb e a Prova Brasil, do MEC, e pelo rendimento escolar, obtido pelo Censo Escolar. O Ideb passa a ser considerado o indicador de avaliação para o PDE, inclusive com ampla divulgação e o estabelecimento de metas bianuais de elevação de suas cifras para os municípios de todo o País.

É certo que o acompanhamento da ação governamental e da efetividade de seus programas não se resume à proposição e ao exame de um ou vários indicadores sociais mais gerais, exigindo instrumentos e pesquisas de monitoramento e de avaliação muito mais complexos e sistemáticos. Contudo, se as mensurações quantitativas propostas se inspirarem, de fato, nos pressupostos de elaboração de indicadores de políticas e guardarem, na sua construção, uma série de propriedades metodológicas desejáveis (JANNuZzI, 2005), certamente poderão trazer contribuições significativas ao processo de avaliação da efetividade dos programas públicos. O uso de sistemas de indicadores, ainda que longe de ser suficiente para efetividade das políticas públicas, potencializa a chance de sucesso, já que permite, em tese, a avaliação de resultados tecnicamente bem respaldados e diagnósticos sociais abrangentes e empiricamente referidos.

Além do respaldo técnico que o uso de bons indicadores é capaz de fornecer à avaliação e ao monitoramento de políticas públicas, é importante atentar para o fato de que os indicadores possibilitam um melhor acompanhamento, por parte da sociedade, dos resultados alcançados. Como assinalam Scandar Neto et al. (2006):

É cada vez mais evidente a necessidade de implementar um sistema de indicadores para monitoramento e avaliação baseado nas políticas, programas e ações. Tal sistema seria uma ferramenta poderosa de administração e gestão pública, não somente para os formuladores de políticas, mas também para aumentar o controle social e transparência das intervenções e das ações do setor público (SCANDAR Neto et al. 2006 p. 9).

A relevância dos indicadores tem sido cada vez mais reconhecida pelo poder público, como revelam as menções do Tribunal de Contas da União (TCU) em seus relatórios de avaliação. Ilustrativas, nesse sentido, são as observações constantes no Relatório de Avaliação de Programa da Ação de Apoio à Formação Continuada de Professores do Ensino Fundamental, elaborado pelo TCU em $2006^{1}$, em que aparecem trechos referentes à necessidade de uso de indicadores em diversas etapas do ciclo da política em análise, como:

Q uanto aos indicadores de desempenho definidos para o gerenciamento 
da ação, analisou-se, preliminarmente, aqueles constantes no PPA 2004/ 2007. ...

0 modelo da ação lógica não previa avaliação de sua efetividade, tampouco a construção de outros indicadores.

No sentido de minimizar essas deficiências, apresenta-se uma sugestão de cesta de indicadores de desempenho (TCU, 2006 p.73-75).

Nas últimas duas décadas, tem-se observado um processo cada vez mais intenso de proposição de indicadores de monitoramento e avaliação da ação governamental, assim como de indicadores sociais mais gerais, dentro e fora das organizações públicas. No campo das políticas educacionais vigoram, na realidade, já há algum tempo, diversos indicadores construídos para acompanhar e monitorar a situação da educação, além de avaliar os resultados de intervenções governamentais. Exemplos são as taxas de analfabetismo, analfabetismo funcional, frequiência escolar, evasão, reprovação, coeficientes de alunos por professor e outras tantas medidas disponíveis na compilação apresentada em MEC/ Inep (2004).

O Ideb é mais uma dessas medidas, com objetivos e propriedades específicas, que, neste trabalho, se busca explorar, entender e discutir. Mais especificamente, 0 objetivo deste trabalho é analisar as características do Índice de Desenvolvimento da Educação Básica, as finalidades da sua construção, seus usos e limitações e também propor outros indicadores para acompanhar os resultados e impactos do PDE.

Este texto está organizado em cinco seções. Na primeira, discute-se 0 papel e o uso dos indicadores no ciclo de políticas públicas, em especial no monitoramento e na avaliação de programas. A seção seguinte tem caráter mais metodológico, tratando da construção de indicadores sintéticos, seus usos e limitações. Apresenta-se, então, o Ideb e se discute tanto suas características e potencialidades quanto suas restrições para 0 acompanhamento da agenda da política educacional. As duas últimas partes são dedicadas à apresentação de

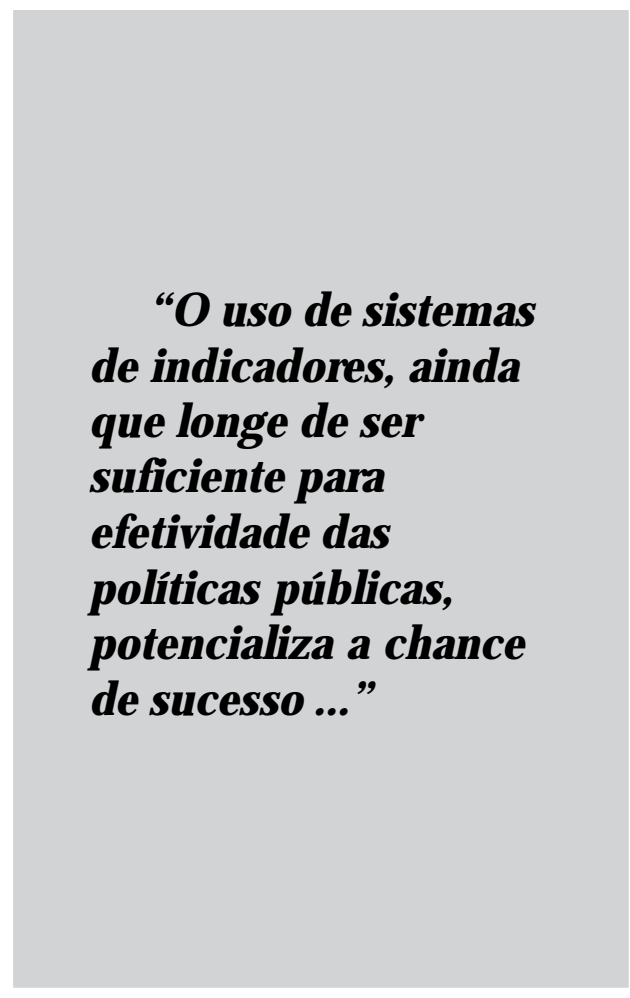

propostas alternativas de indicadores - 0 Ideb+ e o Painel Pideb+ - para monitoramento do PDE.

\section{O ciclo de políticas públicas, a avaliação de programas e os indicadores}

Política pública é, na definição de Nascimento (1991), o conjunto de 
decisões tomadas por aqueles que detêm competência legal para deliberar em nome da coletividade, visando à solução de um problema ou redirecionamento de uma tendência a fim de orientar sua evolução a um fim estabelecido desejável. Para sua formatação e conseqüente operação, a política pública passaria por um ciclo de várias etapas, listadas pela autora como formulação da política; administração ou implementação da política e a avaliação. Para a autora, a etapa de formulação pode ser subdividida em definição da agenda pública, formulação e formalização.

A definição da agenda é a fase em que ocorre a filtragem dos problemas ou de demandas sociais a serem priorizadas, entre as diversas existentes em países com tantos deficits sociais, como o Brasil. Vários atores contribuem para a formação dessa agenda, em particular a burocracia pública. 0 processo é, no entanto, complexo, não linear. Certa demanda social pode ser reconhecidamente importante para grande parte da população de um determinado país, mas não entrar ou não ser priorizada na agenda por falta de interlocutores formais com peso político. Fatores ambientais como desastres podem fazer com que alguns temas entrem imediatamente na agenda. 0 processo eleitoral é outro mecanismo de atualização da agenda, tão mais efetivo quanto mais consistentes e factíveis as propostas de ação constantes nas plataformas dos candidatos. Mas, em muitas situações, as decisões sobre a relevância das questões sociais são avaliadas dentro dos órgãos de governo, com base na análise particular que seus técnicos têm da gravidade e dos reflexos de um determinado problema, da conjuntura e das circunstâncias favoráveis e desfavoráveis para o processo de implementação de um programa ou projeto.
Uma vez que se considera determinado objeto como relevante para a agenda formal de governo, passa-se à etapa seguinte: a formulação da política e de seus programas. Essa fase corresponde principalmente à aquisição de conhecimentos sobre o tema a ser abordado e à elaboração de proposta(s) capaz(es) de resolver o problema ou atender à demanda que 0 originou.

Segue-se então a etapa de formalização ou tomada de decisão, que corresponde à legitimação da política pelas autoridades constituídas (Nascimento, 1991). D e forma simples, esta pode ser entendida como o momento em que se prepara a máquina pública para a execução da política determinada. É nessa fase que também se reúnem tanto informações de intervenções passadas quanto outras relevantes para determinar o rumo da intervenção atual. É o momento ainda de decidir como se dará a otimização de recursos de forma a não inviabilizar essa ou outra política.

E é na etapa de implementação que a política pública começa a ser executada e os recursos alocados geram ações capazes de agir e mudar certa realidade. Aqui a política adquire uma concretude objetiva maior e, por isso, começa a revelar explicitamente as dificuldades de sua introdução e operação pelos agentes encarregados de "pôr a mão na massa". Essa fase possui algumas dificuldades inerentes, como a exeqüibilidade teleológica, que responde pela adequação entre os meios e os fins; a adequação técnica dos meios empregados à produção de resultados desejados; a efetividade econômica que considera a disponibilidade de recursos exigidos pela política; e o apoio do governo e de setores beneficiados pela política no início e no decorrer de sua implementação (JAG UARIBE apud NASCIMENTO, 1991). 
Seguindo o modelo do ciclo de políticas públicas apresentado por Nascimento (1991), a fase subseqüente consiste na avaliação, quando, em tese, averigua-se não somente em que medida os resultados estão sendo alcançados, mas a que custo se executam os programas, seus impactos negativos e positivos e a conveniência ou não de revisão parcial ou total da política (e sua relevância na agenda). Nas palavras de Cohen \& Franco (1999:76), "a avaliação é uma atividade que tem como objetivo maximizar a eficácia dos programas na obtenção de seus fins e a eficiência na alocação de recursos para a consecução deles". Corresponde ao exame sistemático das intervenções planejadas na realidade, tendo por base procedimentos científicos de coleta e análise de informações sobre 0 conteúdo, estrutura, processos, resultados e/ ou impactos de políticas, programas ou projetos (RUA, 2004).

Este ciclo de formulação das políticas públicas, tal como descrito, é certamente um modelo idealizado, com aderência bastante limitada ao cotidiano brasileiro ou de outros países. Aindaassim, ele se presta aos objetivos de evidenciar, ao longo do processo, ênfases diferenciadas no planejamento, na operação ou naavaliação dos programas. A últimafase, por exemplo, não é totalmente destacada das demais ou realizada somente alguns anos depois da implementação dos programas. Pelo contrário, a avaliação deve ser entendida como um processo que permeia todo o ciclo de uma política pública, sendo portanto mais adequado denominar esse conjunto de atividades como "Monitoramento eAvaliação" (RuA, 2004). Como bem expõe documento do Tribunal de Contas da União:

O monitoramento e avaliação dos programas de governo são ferramentas essenciais para a boa prática gerencial. A avaliação é um procedimento que deve ocorrer em todas as etapas, permitindo ao gestor federal o acompanhamento das ações e sua revisão e redirecionamento quando necessário. Enquanto o monitoramento é uma atividade gerencial interna, que se realiza durante o período de execução e operação, a avaliação pode ser realizada antes ou durante a implementação, como ao concluir uma etapa ou projeto como um todo, ou mesmo algum tempo depois, devendo se preocupar com o impacto provocado pela intervenção pública em seus beneficiários. (TCU, 2006, p. 75).

Para desenvolvimento adequado das atividades de monitoramento e avaliação, do grau de cumprimento das metas e objetivos da política, com objetividade e regularidade, é necessário que o gestor disponha de um sistema de informações e pesquisas que lhe ofereça indicações do grau de implementação dos programas, de seus resultados e de eventuais impactos na sociedade, isto é, indicadores de monitoramento e avaliação dos programas. Como observam Cohen e Franco (1999):

Uma instância central do processo de avaliação consiste em determinar em que grau foram alcançadas as finalidades do projeto. Isto requer dimensionar 0 objetivo geral em subconjuntos de objetivos específicos, os quais por sua vez terão "metas", cuja obtenção será medida através de indicadores. As variações nos valores que serão verificados nas unidades de análise permitem quantificar este processo. (Cohen; Franco, 1999; p. 152). 
Jannuzzi (2005) destaca que no campo aplicado das políticas públicas, os indicadores sociais são medidas usadas para permitir a operacionalização de um conceito abstrato ou demanda de interesse programático.

Os indicadores apontam, indicam, aproximam, traduzem em termos operacionais as dimensões sociais de interesse definidas a partir de escolhas teóricas ou políticas realizadas anteriormente. Se prestam a subsidiar as atividades de planejamento público e formulação de políticas sociais nas diferentes esferas de governo, possibilitam o monitoramento das condições de vida e bem-estar da população por parte do poder público e sociedade civil e permitem aprofundamento da investigação acadêmica sobre a mudança social e sobre os determinantes dos diferentes fenômenos sociais (JanNUZZI, 2005, p.138).

A construção de indicadores para monitoramento e avaliação de programas deveria ser pautada, segundo o autor, pela aderência dos mesmos a um conjunto de propriedades desejáveis, ainda que seja difícil garanti-las simultaneamente. Como essas propriedades servirão de critérios de avaliação do Ideb mais à frente, é essencial uma exposição detalhada de algumas dessas propriedades.

Uma propriedade fundamental para qualquer indicador é a sua validade, isto é, sua capacidade de retratar o conceito ou o objetivo para o qual a medida foi idealizada. Essa parece ser uma tautologia, mas a realidade é que existem indicadores em especial, indicadores sintéticos (discutidos mais à frente), nos quais a proximidade entre conceito e medida é bastante discutível (Jannuzzi, 2002; Guimarães \& JANNUZZI, 2005).

Para uso na tomada de decisão em políticas públicas, o indicador deve ser confiável, ou seja, computado a partir de dados de boa qualidade, provenientes de fontes e pesquisas consistentes e sujeitos a controle de qualidade e de tendenciosidade. D evem gozar de inteligibilidade, isto é, a transparência da metodologia de sua construção. Igualmente importante é a comunicabilidade do indicador, sua capacidade de "passar claramente o recado" por ele aportado para diferentes públicos.

A sensibilidade e a especificidade são propriedades importantes para indicadores de monitoramento e avaliação. Sensibilidade do indicador corresponde à sua capacidade de refletir, de modo tempestivo, as mudanças a que ele se propõe retratar. Especificidade do indicador corresponde à sua propriedade de refletir alterações estritamente decorrentes do programa ou ação que ele se propõe a monitorar.

Naturalmente, a periodicidade é outra propriedade fundamental para que um indicador seja útil no processo de monitoramento das ações públicas. Afinal, somente com informações regularmente produzidas é que se pode avaliar os efeitos dos programas - ou ausência deles - e corrigir eventuais distorções a tempo. Em alguns casos é extremamente caro realizar pesquisas e coleta de dados, o que remete a outra propriedade: a factibilidade da disponibilidade do indicador. 0 custo e 0 tempo para obtenção do indicador têm de ser compatíveis com as necessidades e os usos que se faz dele.

Séries históricas trazidas por um indicador são bastante relevantes por permitirem acompanhar tendências e comparar eventuais efeitos e impactos dos programas ao longo do tempo. Isso constitui a 
historicidade de um indicador, outro atributo interessante para indicadores de monitoramento.

Os indicadores usados no monitoramento e na avaliação de políticas públicas podem ser classificados de várias formas diferentes, como mostra o Q uadro 1, elaborado por O ttoni (2006). Uma taxonomia importante e presente nesse quadro é a que diferencia os indicadores entre indicador-insumo, indicador-processo e indicador-resultado.

Como define Jannuzzi (2004), os indicadores-insumo correspondem às medidas associadas à disponibilidade de recursos humanos, financeiros ou equipamentos alocados para um processo ou programa que afeta uma das dimensões da realidade social. São tipicamente indicadores de alocação de recursos para políticas sociais, como número de escolas com laboratório de ciências ou quadras de esportes, coeficiente técnico de professores por aluno, biblioteca pública por população de cinco anos ou mais ou, ainda, gasto monetário per capita nas diversas áreas de política social.

Os indicadores-resultado são aqueles propriamente vinculados aos objetivos finais dos programas públicos, que permitem avaliar a eficácia no cumprimento das metas especificadas, como a taxa de analfabetismo, cuja diminuição se espera verificar com a implementação de um programa como o Educação de Jovens e Adultos (EJA). Parte desses resultados pode ter efeitos e desdobramentos gerais, antecipados ou não, positivos ou não, que decorrem da implantação dos programas. Um programa como o EJA, por exemplo, pode levar seus participantes a terem papel mais ativo na comunidade ou a buscarem melhores empregos, por ampliarem seus horizontes de possibilidades e repertórios cognitivos. Nesses casos, costuma-se denominar os indicadores que medem essas dimensões de indicadores de impacto.

Já os indicadores-processo ou fluxo são indicadores intermediários, que traduzem em medidas quantitativas 0 esforço operacional de alocação de recursos humanos, físicos ou financeiros (indicadores-insumo) para obtenção de melhorias efetivas de bem-estar (indicadores-resultado e impacto), como o volume de merendas escolares distribuídas

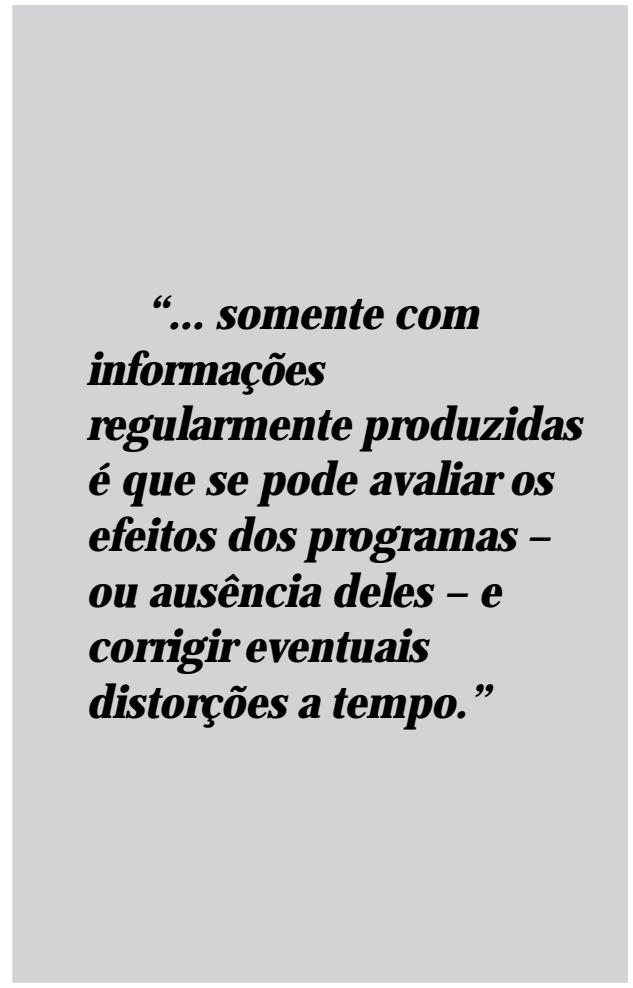

diariamente por alunos, os professores capacitados em uma nova metodologia, ou ainda homens-hora dedicados a um programa social.

\section{Indicadores sintéticos: construção, usos e limitações}

D esses vários tipos de indicadores dispostos no Q uadro 1, interessa destacar, 
para os objetivos deste trabalho, os indicadores sintéticos, também denominados de indicadores compostos ou índices sociais. A principal característica dos indicadores sintéticos é a de aglutinar dois ou mais indicadores primários (ou simples), por meio de métodos aritméticos ou estatísticos, em uma única medida. Um dos indicadores sintéticos mais conhecidos é 0 Índice de Desenvolvimento Humano (IDH), que compila três dimensões bem distintas, como esperança de vida, PIB per capita e indicador composto de taxa de analfabetismo e de taxa bruta de freqüência escolar. O Índice de D esenvolvimento da Educação Básica (Ideb) - objeto de análise deste trabalho - constitui outro exemplo que, nesse caso, sintetiza duas dimensões: o desempenho de alunos em testes padronizados e o rendimento escolar (aprovação).

Esses indicadores sintéticos são construídos a partir de uma operação metodológica realizada em várias etapas

\section{Q uadro 1: Classificação, descrição e exemplos de indicadores.}

\begin{tabular}{|c|c|c|}
\hline Claveificayano & Denerificina & Exempils \\
\hline $\begin{array}{l}\text { Inificator } \\
\text { Qeactinativo }\end{array}$ & 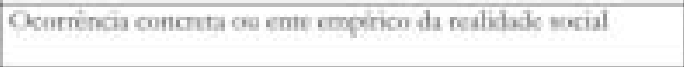 & Beos de acidentes no tritulios \\
\hline $\begin{array}{l}\text { Inilicadoe } \\
\text { Qualitatina }\end{array}$ & 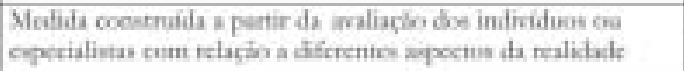 & Incice de confianca no grocmu \\
\hline $\begin{array}{l}\text { Indicalor } \\
\text { Dexcrituve }\end{array}$ & 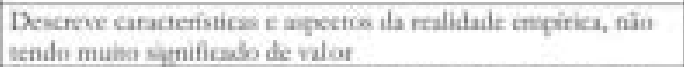 & Tasa de metalifale intant \\
\hline $\begin{array}{l}\text { Inticalve } \\
\text { Arenuatin }\end{array}$ & 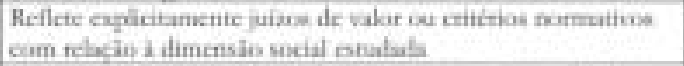 & Properatcia de polates \\
\hline $\begin{array}{l}\text { Indirauline de } \\
\text { Insume }\end{array}$ & 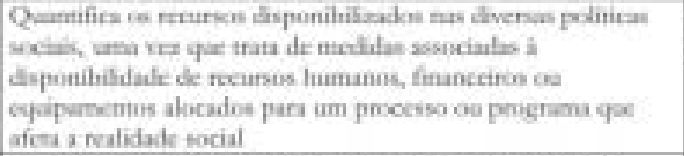 & 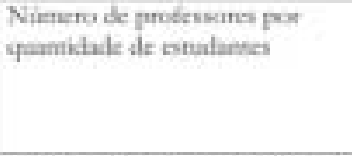 \\
\hline $\begin{array}{l}\text { Indicadoe de } \\
\text { Processo av Thas }\end{array}$ & 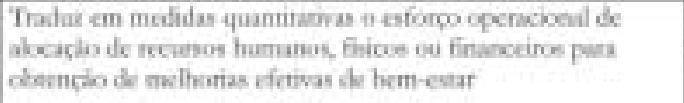 & $\begin{array}{l}\text { Nomero de consibas pediarricas } \\
\text { por incs }\end{array}$ \\
\hline $\begin{array}{l}\text { Inticaloe de } \\
\text { Pricalios ces } \\
\text { Resulinilo }\end{array}$ & 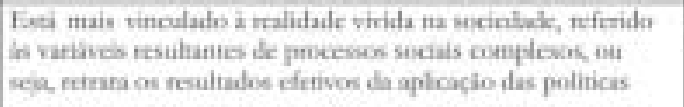 & Enperatuca de vida an masert \\
\hline $\begin{array}{l}\text { Intirasur de } \\
\text { Faboger }\end{array}$ & 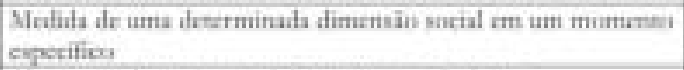 & $\begin{array}{l}\text { Anos de cucriaribale das } \\
\text { malhers ncgers }\end{array}$ \\
\hline $\begin{array}{l}\text { Indicador de } \\
\text { Periurmaner }\end{array}$ & Abanca mudancas enen doss momenem distintre & 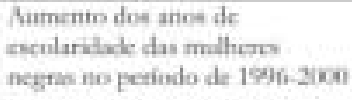 \\
\hline $\begin{array}{l}\text { Inalicalose de } \\
\text { Avaliacionde } \\
\text { Eficiencia }\end{array}$ & 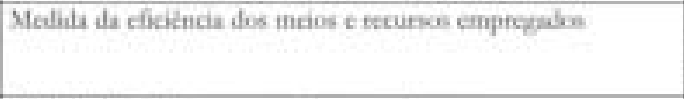 & $\begin{array}{l}\text { Wolume de investimctos poe } \\
\text { inalable de area fisica. }\end{array}$ \\
\hline $\begin{array}{l}\text { Indicaloe de } \\
\text { Avaliacio de } \\
\text { Firicio }\end{array}$ & Metida de cícica eo cumprimetseo das metas & $\begin{array}{l}\text { Melhoes das condiciones de } \\
\text { monalis }\end{array}$ \\
\hline $\begin{array}{l}\text { Indicialoe de } \\
\text { Avaliacalos de } \\
\text { Ffrtividade }\end{array}$ & 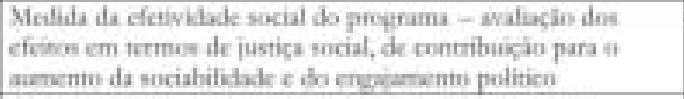 & Nhat de criminaliviole \\
\hline Indicaloe Sinclios & Crescorualo a partif de uma estatistica social especitica & Tas ile motailate materna \\
\hline $\begin{array}{l}\text { Inticaloe compestas } \\
\text { Gintèticiss au } \\
\text { Indices Sociais? }\end{array}$ & 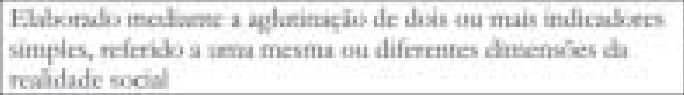 & $\begin{array}{l}\text { WH - Intice fe } \\
\text { Desenvedvinenits Humarss }\end{array}$ \\
\hline
\end{tabular}

Fonte: Ottoni, 2006. 
sucessivas, como pode ser observado na Figura 1, baseada em Scandar Neto et al. (2006). O primeiro passo no processo consiste em definir o marco ordenador, marco conceitual ou ainda marco institucional, que orientará as demais etapas. Para garantir que a medida sintética final seja, de fato, útil para o monitoramento e a avaliação dos programas, é fundamental que os documentos propositivos da política pública específica sejam se discute em Scandar Neto (2006). A sofisticação do método empregado não assegura, necessariamente, que o indicador sintético produzido tenha maior validade ou sensibilidade que outro computado por meio de algoritmos muito simples.

Uma vez computado, o índice deve ser analisado quanto à sua real capacidade de expressar quantitativamente 0 que se propugnava ao se estabelecer o marco conceitual.

\section{Figura 1: Etapas para a construção de um indicador sintético.}

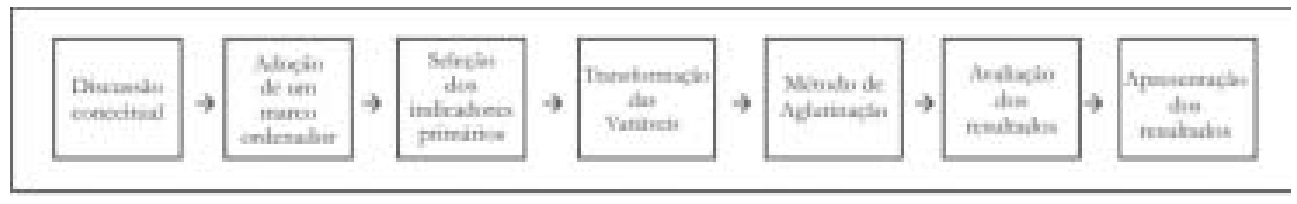

Fonte: Scandar Neto et. al. (2006) com adaptações.

exaustivamente usados na montagem desse marco, explicitando as dimensões mais objetivas e relevantes de acompanhamento.

Uma vez definido o marco conceitual e suas dimensões, é necessário selecionar os indicadores primários que comporão 0 índice. Os indicadores primários devem estar em consonância com o marco ordenador, referidos especificamente nas dimensões. Mas nem sempre é possível dispor de indicadores com a periodicidade requerida e muito menos com as propriedades desejáveis. Essa é uma etapa que também exige cuidado, a fim de evitar que o indicador sintético perca ao final sua validade, especificidade e sensibilidade.

A etapa seguinte envolve o tratamento quantitativo para combinar as medidas, expressas em diferentes escalas, de modo a produzir o indicador sintético. Existem vários métodos quantitativos - aritméticos, estatísticos, de pesquisa operacional passíveis de serem empregados, cada um com suas virtudes e limitações, conforme
Um exemplo de indicador sintético construído no campo educacional, que precedeu, inclusive, o Ideb, foi o Indicador Municipal de Desenvolvimento da Educação (IMDE), proposto por Cunha et al. (2001). Conforme ilustrado na Figura 2, para construir esse indicador foram usados diversos indicadores do censo escolar e outros fornecidos pelo IBGE. Observa-se a utilização de vários tipos de indicadores com características muito distintas, na tentativa de sintetizar em apenas um indicador a realidade do desenvolvimento e da qualidade da educação em nível municipal. No entanto, os próprios autores reconhecem as limitações de um indicador sintético nesses moldes, pois seriam pouco reveladores das especificidades dos fenômenos que buscam mensurar. Esse é um caso no qual a medida-síntese parece não ter a utilidade imaginada.

Há um debate polarizado na literatura acerca da utilidade e pertinência do uso de 
Figura 2: Variáveis selecionadas para construção do IMDE

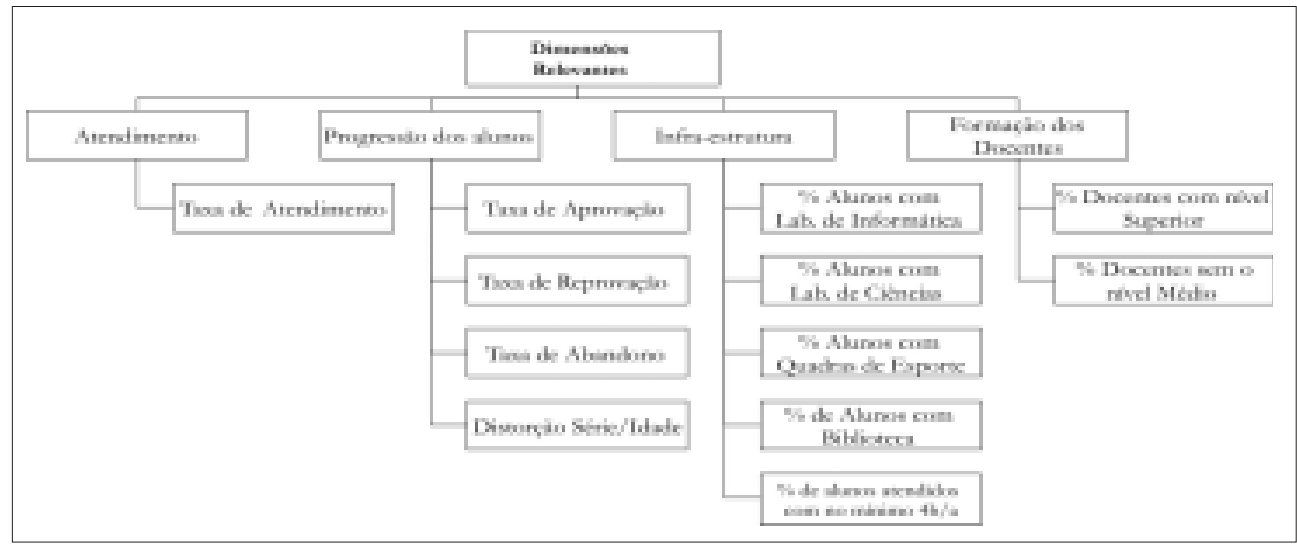

Fonte: Cunha et al. (2001) com adaptações.

indicadores sintéticos nas políticas públicas. Há quem os defenda, relacionando diversos argumentos a favor: são medidas interessantes por sintetizar conceitos complexos e multidimensionais e, portanto, auxiliam a tomada de decisões; oferecem uma visão geral do problema ou conceito que procuram representar; permitem a comparabilidade e ranqueamento entre países (ou municípios), possibilitando acompanhar o desempenho deles; resumem em uma só medida 0 impacto de várias ações e programas governamentais; e ajudam a chamar a atenção da população e da mídia para questões sociais e para a efetividade da ação governamental (como tem ocorrido com o IDH).

O s autores que criticam os indicadores sintéticos arrolam outros argumentos contra: se forem construídos sem procedimentos metodológicos adequados, podem emitir mensagens políticas equivocadas; os gestores podem tomar decisões simplistas devido à visão geral que 0 indicador apresenta; o processo de compilação dos dados pode fazer com que dados relevantes percam o sentido no cálculo do indicador, diminuindo a sua sensibilidade em captar mudanças importantes em uma de suas dimensões; em muitos casos, a medida acaba adquirindo mais importância do que o conceito que a originou (o fetiche do indicador em detrimento do constructo).

G uimarães \& Jannuzzi (2005), críticos do uso dos indicadores sintéticos, reconhecem que esses indicadores acabaram conquistando legitimidade social, política, técnica e científica. Parece ser esse o caso do Ideb, analisado em seguida.

\section{O PDE e o Índice de Desenvol- vimento da Educação Básica}

O Plano de Desenvolvimento da Educação (PDE) pode ser entendido como um conjunto de programas que objetivam dar conseqüência às metas quantitativas estabelecidas no Plano Nacional de Educação (PNE). O Plano compreende mais de 40 programas que podem ser organizados em torno de quatro eixos norteadores: educação básica, educação superior, educação profissional e alfabetização. No eixo da educação básica, um documento que merece destaque para as finalidades deste trabalho é o Plano de 


\section{Quadro 2: Diretrizes e iniciativas do Plano de Metas Compromisso Todos pela Educação}

\begin{tabular}{|c|c|}
\hline $\mathbf{N}^{*}$ & Diretrix \\
\hline 1 & 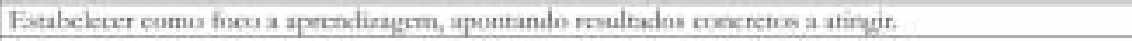 \\
\hline II & 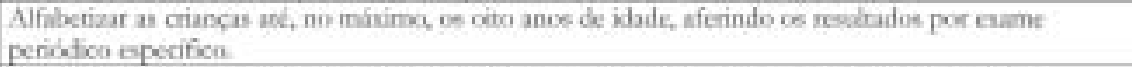 \\
\hline $\mathrm{III}$ & 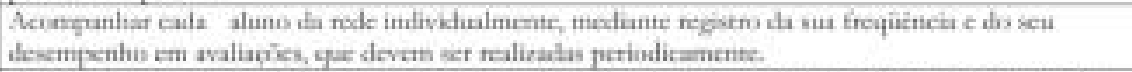 \\
\hline IV & 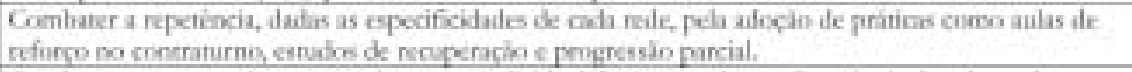 \\
\hline V & 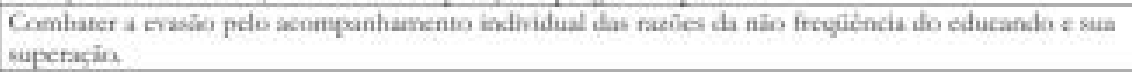 \\
\hline VI & 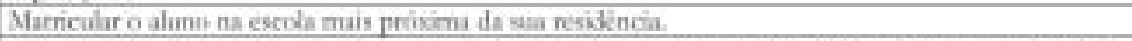 \\
\hline VII & 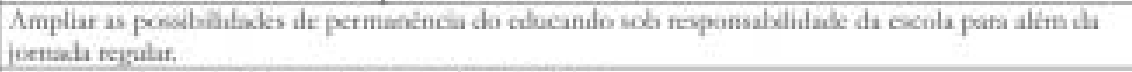 \\
\hline VIII & Vahorixar a formacin cica, artiontica 6 a cducacion finica. \\
\hline IX & 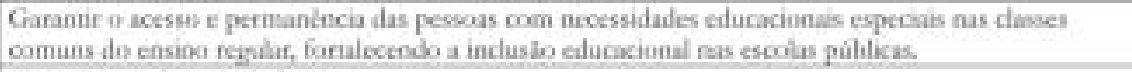 \\
\hline $\mathrm{x}$ & Promuser a nbackikis intantil. \\
\hline Xi & 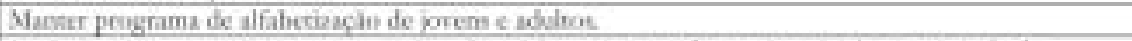 \\
\hline Xil & 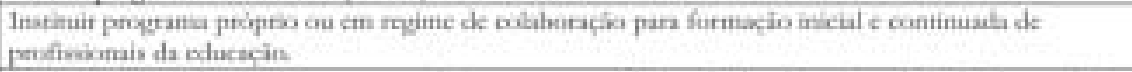 \\
\hline XIII & 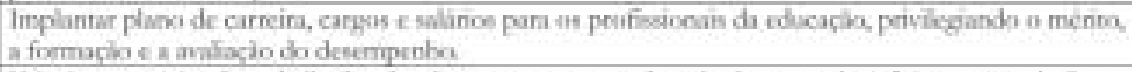 \\
\hline XIV & 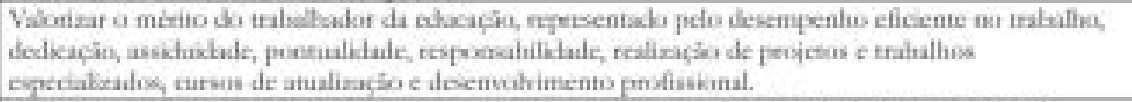 \\
\hline XV & 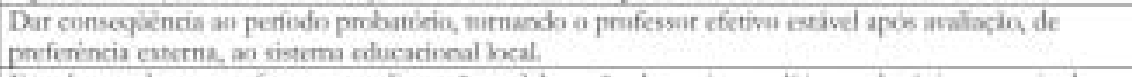 \\
\hline $\mathrm{xVI}$ & 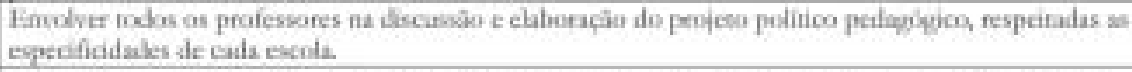 \\
\hline XVII & 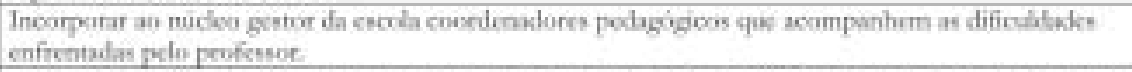 \\
\hline XVIII & 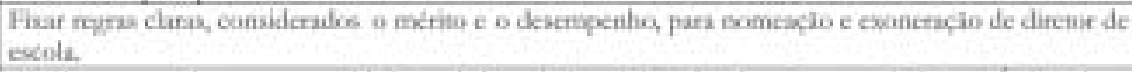 \\
\hline XIX & 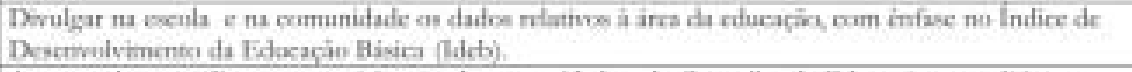 \\
\hline $\mathrm{xx}$ & 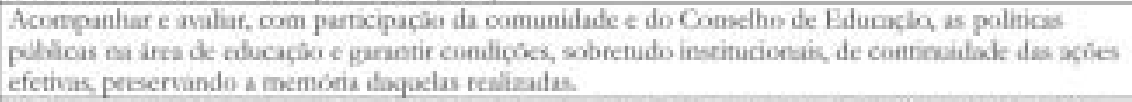 \\
\hline $\mathrm{xxl}$ & 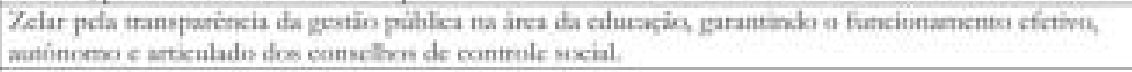 \\
\hline XXII & Fromover a gostà participariva na rede de cnsima \\
\hline XXIII & 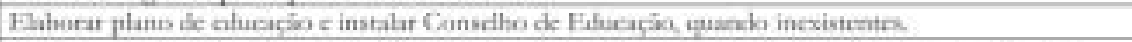 \\
\hline XXIV & 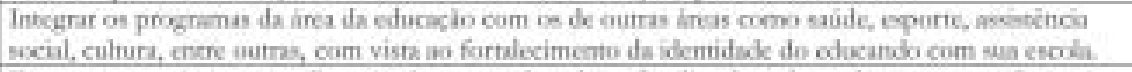 \\
\hline $\mathrm{XXV}$ & 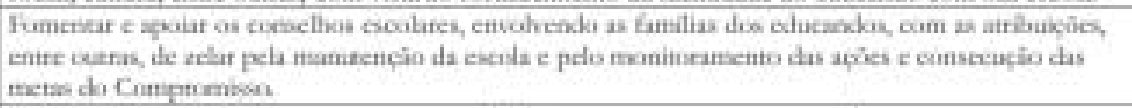 \\
\hline $\mathrm{XXV}$ & 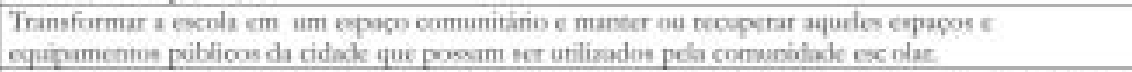 \\
\hline $\mathrm{XXV} 11$ & 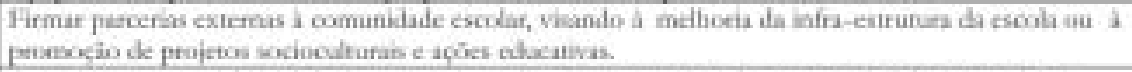 \\
\hline XXVIII & 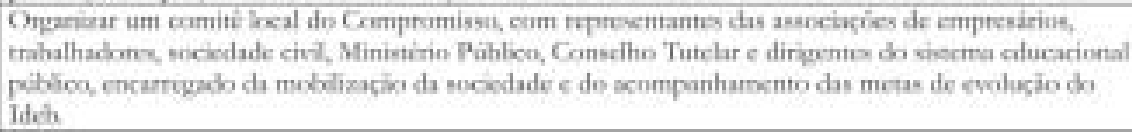 \\
\hline
\end{tabular}

Fonte: Elaboração própria com base no D ec. 6.094, de 24 de abril de 2007. 
Metas Compromisso Todos pela Educação (Dec. $\mathrm{n}^{0}$ 6.094, de 24 de abril de 2007), doravante denominado de Compromisso. Ao todo são 28 diretrizes (Quadro 2) a serem implementadas, com auxílio da União, nos estados, Distrito Federal e municípios que 0 assinarem.

Para acompanhar a efetividade dos programas, estabelecer metas concretas a perseguir e focalizar ações do MEC, foi criado o Índice de D esenvolvimento da Educação Básica (Ideb). Como citado em documento do MEC (2007):

A partir da criação do Ideb, calculado por escola, por rede e para o próprio país, foi possível fixar metas de desenvolvimento educacional de médio prazo para cada uma dessas instâncias, como metas intermediárias de curto prazo que possibilitam visualização e acompanhamento da reforma qualitativa dos sistemas educacionais.

0 Ideb permite identificar as redes e as escolas públicas mais frágeis a partir de critérios objetivos e obriga a União a dar respostas imediatas para os casos mais dramáticos ao organizar o repasse de transferências voluntárias com base em critérios substantivos. 0 escopo é atender imediatamente 1.242 municípios e as 7.085 escolas com os mais baixos indicadores e, em curto prazo, todos os que estejam abaixo da média nacional (p. 22-23).

Sua proposição foi inspirada na constatação de que a "indústria da aprovação automática" é tão perniciosa quanto a "indústria da repetência", o que levou seus proponentes a combinarem os resultados de desempenho escolar (Prova Brasil) e os de rendimento escolar (fluxo apurado pelo Censo Escolar) em um único indicador.
Mais precisamente, como apresentado em Inep (2007), o Ideb é calculado como o produto de dois indicadores (fórmula 1 abaixo): a) a pontuação média dos estudantes em exames padronizados ao final de cada etapa da educação básica (exames do Sistema de Avaliação da Educação Básica ou Prova Brasil nas $4^{\mathrm{a}}$ e $8^{\mathrm{a}}$ séries do ensino fundamental e $3^{\circ}$ ano do ensino médio); b) taxa média de aprovação dos estudantes da correspondente etapa de ensino.

\section{Ideb $=N, P_{,}+\quad 0 \leq N \leq 10 ;$ $0 \leq P \leq 1$ e $0 \leq 1 d d, \leq 10$}

Onde:

$\mathrm{i}=$ ano do exame (Saeb e Prova Brasil) e do Censo Escolar;

j = unidade de referência (estado, escola, etc.)

$\mathrm{N}_{\mathrm{ji}}=$ média da proficiência em Língua Portuguesa e Matemática, padronizada para um indicador entre 0 e 10, dos alunos da unidade j, obtida em determinada edição do exame realizado ao final da etapa de ensino;

$\mathrm{P}_{\mathrm{ji}}=$ indicador de rendimento baseado na taxa de aprovação da etapa de ensino dos alunos da unidade $j$.

A taxa de aprovação é calculada pela fórmula (2), a saber:

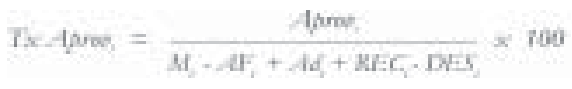

Onde:

$s=$ série do ensino fundamental ou ensino médio . A prov = número de aprovados na série ou grupo de séries $s$;

$\mathrm{M}_{\mathrm{S}}=$ matrícula inicial na série ou grupo de séries s; $\mathrm{A} \mathrm{F}_{\mathrm{S}}=$ afastados por abandono ou transferência na série ou grupo de séries s;

$A D_{S}=$ admitidos por transferência na série ou grupo de séries s; 
$R E C_{S}=$ Reclassificados para a série ou grupo de séries s;

$\mathrm{DES}_{\mathrm{S}}=$ alunos que saíram da série ou grupo de séries s, por reclassificação.

A média de proficiência padronizada dos estudantes da unidade $\mathrm{j}, \mathrm{N}_{\mathrm{ji}}$ é obtida a partir das proficiências médias em Língua Portuguesa e Matemática dos estudantes submetidos a determinada edição do exame realizado ao final da etapa educacional considerada. Como a escala do Saeb ou Prova Brasil varia entre 0 e 500 pontos, é preciso usar um método para que essa nota seja convertida para uma escala entre 0 e 10. No caso do Ideb, essa nota é convertida usando um método denominado padronização (fórmula 3).

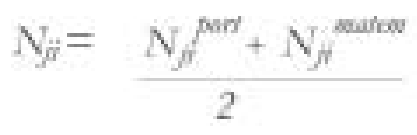

em que

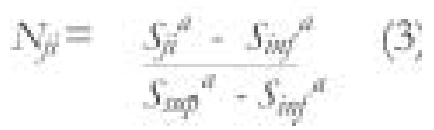

O nde:

$\mathrm{a}=$ disciplina (Matemática ou Língua Portuguesa); nâ = proficiência na disciplina á, obtida pela unidade j, no ano i, padronizada para valores entre 0 e 10; $\mathrm{s}_{\mathrm{j}}^{\mathrm{a}}=$ proficiência média (em Língua Portuguesa ou Matemática) não padronizada dos alunos da unidade j obtida no exame do ano i;

$\mathrm{Sa}_{\mathrm{nf}}=$ limite inferior da média de proficiência (Língua Portuguesa ou Matemática) do Saeb 1997; $\mathrm{s}_{\text {sup }}=$ limite superior da média de proficiência (Língua Portuguesa ou Matemática) do Saeb 1997;

Para garantir a comparabilidade dos indicadores ao longo do tempo foram adotados os limites inferior e superior observados nas provas de 1997, ano de definição da escala do Saeb. 0 limite inferior considerado para a padronização foi a média subtraída de três vezes 0 desvio padrão, e 0 superior a média adicionada de três vezes o desvio padrão, levando à exclusão de notas excepcionalmente boas e ruins. As tabelas 1 e 2 mostram a média e o desvio padrão da proficiência dos alunos de $4^{\mathrm{a}}$ e $8^{\mathrm{a}}$ séries do ensino fundamental e do $3^{\circ}$ ano do ensino médio, e os valores usados como limites inferiores e superiores na padronização, respectivamente.

Com base nessas fórmulas, o Inep calculou o Ideb para o Brasil, estados, municípios e, até mesmo, por escola, conforme disposto na Tabela 3. Como os dados da Tabela 1 já permitiriam deduzir, pelos baixos níveis de proficiência, a escola pública no Brasil não estaria "passando de ano": 0 Ideb calculado para 2005 estaria bem abaixo de 5 nos diversos níveis de ensino e contextos. 0 índice médio para as escolas do País seria de 3,8 para os anos iniciais do ensino fundamental, com resultados significativamente piores na zona rural $(2,7)$. Nas escolas particulares e federais (em geral, colégios de aplicação vinculados a universidades federais), o desempenho é mais alentador, superior a 5,9.

Apresentado 0 indicador, passa-se agora à sua análise crítica, a partir dos aspectos descritos nas seções anteriores acerca das propriedades desejáveis de um indicador de monitoramento e de avaliação, bem como de suas potencialidades.

D o ponto de vista conceitual, sem dúvida, o aspecto mais relevante do Ideb é a sua utilidade para o PDE. Por ser um indicador de resultados, pode-se entender que contempla a sua designação de um 
Tabela 1: Proficiências médias e desvio padrão no Saeb - Brasil 1997

\begin{tabular}{c|c|c|c|c}
\hline \multirow{2}{*}{ Séric } & Media & Matemática & \multicolumn{2}{c}{ Lingua Portuguesa } \\
\hline $4^{2}$ do EF & 190.8 & 44 & 186.5 & 46 \\
\hline $8^{4}$ do EF & 250.0 & 50 & 250.0 & 50 \\
\hline $3^{\circ}$ do EM & 288.7 & 59 & 283.9 & 56 \\
\hline
\end{tabular}

Fonte: Inep (2007b).

Tabela 2: Limites inferior e superior das proficiências no Saeb - Brasil 1997

\begin{tabular}{c|c|c|c|c}
\hline \multirow{2}{*}{ Série } & \multicolumn{2}{|c}{ Maternatica } & $\mathrm{S}_{\text {iaf }}$ & $\mathrm{S}_{\text {vap }}$ \\
\cline { 2 - 5 } & $\mathrm{S}_{\text {wer }}$ & $\mathrm{S}_{\text {we }}$ & 49 & 324 \\
\hline $4^{4}$ do EF & 60 & 322 & 100 & 400 \\
\hline $8^{4}$ do EF & 100 & 400 & 117 & 451 \\
\hline $3^{7}$ do EM & 111 & 467 & 117 \\
\hline
\end{tabular}

Fonte: Inep (2007b).

Tabela 3: Ideb computado para diversos contextos - Brasil 2005.

\begin{tabular}{|c|c|c|c|}
\hline & $\begin{array}{l}\text { Anos iniciais doensino } \\
\text { fundarmental }\end{array}$ & $\begin{array}{l}\text { Anos finais doensino } \\
\text { fundamental }\end{array}$ & Ensino Médio \\
\hline & 2005 & 2005 & 29015 \\
\hline Total & 3,8 & 3,5 & 3,4 \\
\hline \multicolumn{4}{|c|}{ Localixas̆año } \\
\hline Uthana & 40 & - & - \\
\hline Rural & 27 & - & - \\
\hline \multicolumn{4}{|c|}{ Dependência Administrativa } \\
\hline Püblica & 3,6 & 3,2 & 3,1 \\
\hline Federal & 6.4 & 6,3 & 5,6 \\
\hline Estadual & 39 & 3,3 & 3,0 \\
\hline Munscipal & 3,4 & 3,1 & 2,9 \\
\hline Privada & 5,9 & 5,8 & 5,6 \\
\hline
\end{tabular}

Fonte: Inep (2007b).

indicador de "avaliação" de resultados obtidos pelos municípios que aderirem ao Compromisso. Se é fato que não goza da especificidade que indicadores referidos para cada uma das 28 iniciativas do PDE desfrutariam, por outro lado, permite que
0 resultado sinérgico das mesmas seja avaliado conjuntamente.

0 indicador é dotado de validade, uma vez que considera a combinação de dois indicadores referidos a dimensões associadas (desempenho no aprendizado e no 
fluxo escolar). Como se pode observar nos gráficos a seguir (G ráficos 1a e 1b), há uma correlação alta entre Ideb e taxa de aprovação, e o Ideb e a nota padronizada. O u seja, 0 indicador final parece não ter-se distanciado das dimensões que foram associadas para a sua construção, mantendo assim certa "fidedignidade" com o conceito de qualidade de educação a que ele se propõe a mensurar.

A consistência metodológica do indicador é outro fator que deve ser considerado como um aspecto positivo. Seus idealizadores tiveram a preocupação de usar duas dimensões com características semelhantes, ou seja, indicadores de resultado,

\section{Gráfico 1: Comelação entre o Ideb e seus indicadores componentes} Brasil-Rede Estadual - Anos iniciais do ensino fundamental 2005.
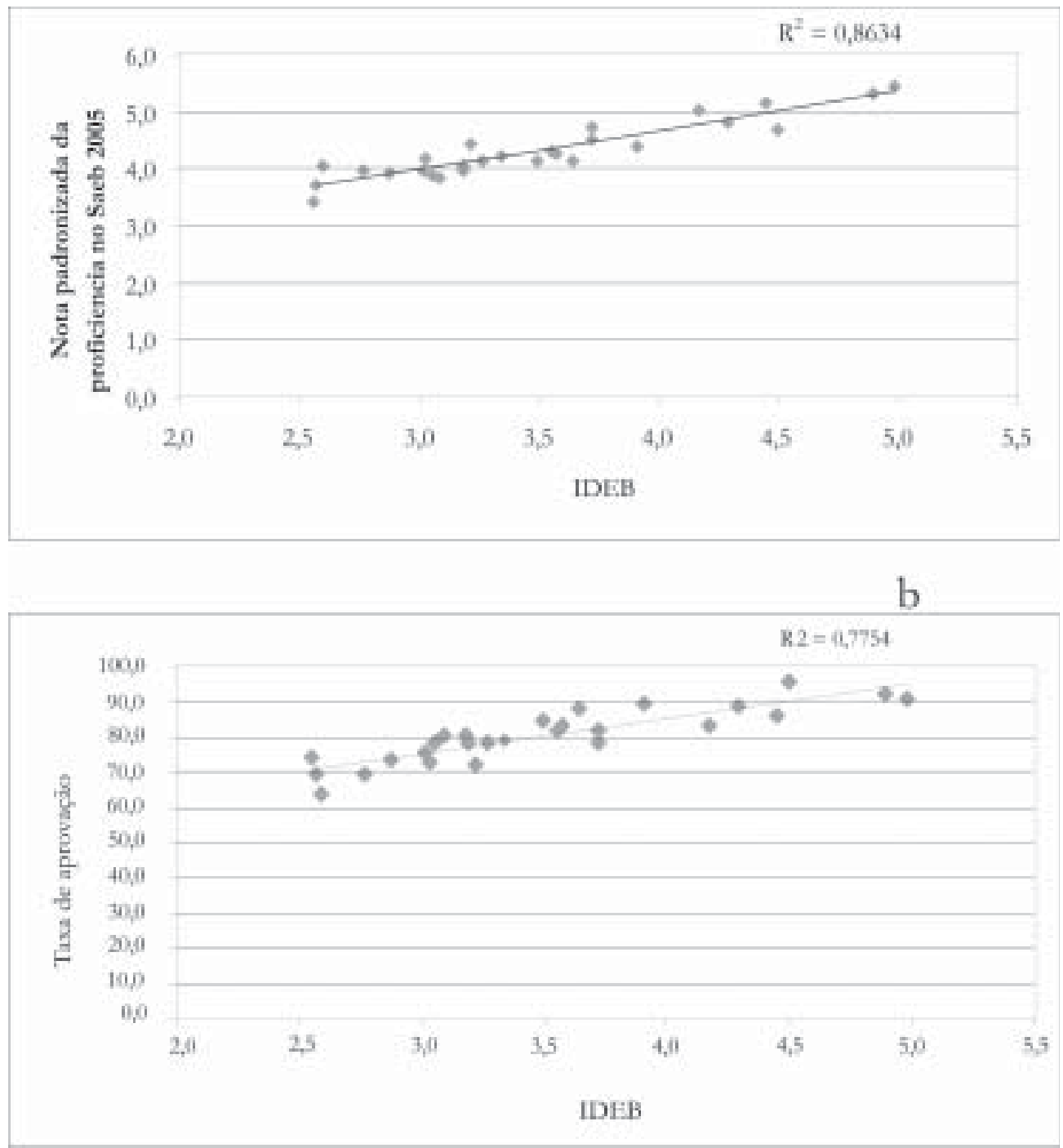
ao contrário do IMDE já referido. $\mathrm{Na}$ proposta de cômputo do IMDE, foram utilizadas dimensões como atendimento, progressão dos alunos, infra-estrutura e formação dos docentes, combinando-se 12 indicadores de tipos diferentes, ou seja, de insumos, processos, resultados, o que acabou por gerar um indicador pouco inteligível e com pouca consistência metodológica.

O utra característica interessante no Ideb é a inteligibilidade de sua escala (de 0 a 10). 0 modelo multiplicativo de construção do Ideb facilita esse entendimento e a análise da contribuição de cada um dos indicadores primários para o cálculo do indicador. Como se pode verificar na fórmula (4), a variação relativa do Ideb pode ser decomposta em duas parcelas, a variação relativa da nota e a da aprovação.

$\frac{\triangle \text { IDEB }}{\text { IDEB }}=\frac{\triangle \text { Nota }}{\text { Nota }}+\frac{\triangle \text { Tx Aprov }}{\text { Tx Aprov }}$

Vale atentar também para o fato de que os indicadores usados no Ideb afetam-se mutuamente em sentidos opostos, ou seja, caso as escolas aumentem a taxa de aprovação, isso poderá reduzir a qualidade do ensino. Já o estabelecimento de padrões elevados para aprovação tende a elevar as notas nos testes padronizados, mas, por conseqüência, diminuir a taxa de aprovação.

Fernandes (2007) descarta essa característica do Ideb ao afirmar que:

(...) não se pode descartar a possibilidade de as escolas e/ ou redes de ensino adotarem medidas que melhorem o fluxo e piorem o desempenho nos exames padronizados e vice-versa. Nesse caso, se a cobrança for restringida apenas aos indicadores de fluxo, ela pode incentivar os professores, diretores de escolas e gestores de rede a adotarem medidas que impliquem redução no desempenho médio dos estudantes nos testes padronizados, como, por exemplo, reduzir o padrão de aprovação. Por outro lado, se a cobrança for apenas sobre os sores dos alunos, o incentivo é o oposto, como, por exemplo, elevar o padrão de aprovação (p.8).

A possibilidade de cômputo do Ideb em nível de escolas, que remete à propriedade de desagregabilidade de um indicador, é outra característica importante da medida. É possível, dessa forma, avaliar em que medida a heterogeneidade socioeconômica estrutural presente nas cidades brasileiras afeta o desempenho educacional das crianças eadolescentes, mesmo quando submetidos, em tese, a iguais condições de oferta de serviços educacionais. Alunos de escolas de periferia mais pobre tenderiam a ter desempenho pior do que aqueles de escolas mais centrais, situadas em bairros de classe média, por não desfrutarem nem de condições materiais - alimentação, moradia etc. - nem do ambiente sociocultural dessa classe, medido pela escolaridade dos pais, pelas oportunidades de acesso à rede de internet, jornais, cinema, TV a cabo, curso de inglês etc. Conhecer o diferencial do Ideb, entre essas escolas, é certamente importante para gestores públicos, não apenas da Educação, mas os ligados às pastas da Assistência e Desenvolvimento Social, da Cultura e Esportes, da Segurança Pública, já que a solução para a melhoria do desempenho escolar só seria possível mediante o esforço articulado de ações mais específicas do sistema de ensino nessas escolas de periferia, como aumento da jornada escolar, promoção de atividades culturais, 
incentivo para fixação de professores mais experientes ou qualificados, além de programas públicos mais abrangentes e de impacto do ponto de vista social - maior cobertura do Bolsa Família, obras de infraestrutura urbana, policiamento, cursos de qualificação profissional para os pais etc.

Em que pesem os aspectos positivos acima relacionados, como todo indicador sintético, o Ideb também tem suas limitações. A primeira crítica a se fazer é em relação à padronização dos escores de proficiência. Entende-se que essa padronização é uma técnica amplamente utilizada, dotada de validade científica e imprescindível para a construção do indicador segundo sua fórmula multiplicativa. No entanto, não deve passar despercebido que a utilização da padronização acarreta uma perda relativa de comensurabilidade das medidas originais, já que as escalas do Saeb e da Prova Brasil deixam de ser referência para o seu entendimento. Se, por exemplo, a média das notas dos alunos de $4^{a}$ série de uma determinada escola é 169,2 pontos em Língua Portuguesa, pela escala estabelecida do Saeb infere-se que esses estudantes ainda não são capazes de "interpretar histórias em quadrinhos mais complexas, reconhecendo a ordem dos fatos" ou "inferir o sentido de uma expressão metafórica ou de uma onomatopéia em anedotas". Quando essa mesma nota é padronizada, transformando-se em uma medida entre 0 e 10 , perde-se a possibilidade de fazer tais inferências, ainda que se ganhe em inteligibilidade para a sociedade em geral, como comentado acima.

A combinação das notas padronizadas de Português e Matemática, para 0 cômputo de uma nota média, é outra crítica que se pode fazer, pois acarreta perda de especificidade dos indicadores. Se, por exemplo, a nota padronizada em Português é 2,5 e a de Matemática é 7,5, a nota média $(5,0)$ não indica em que disciplina se deve investir mais especificamente. O bviamente que os dados básicos podem ser buscados e analisados, mas, de fato, o Ideb, por si só, não é específico para programas de ensino em nenhuma das duas áreas.

Outro ponto que merece atenção é o fato de que não há ponderação explícita dos dois indicadores, o que não significa que tenham pesos iguais. $\mathrm{Na}$ realidade, a

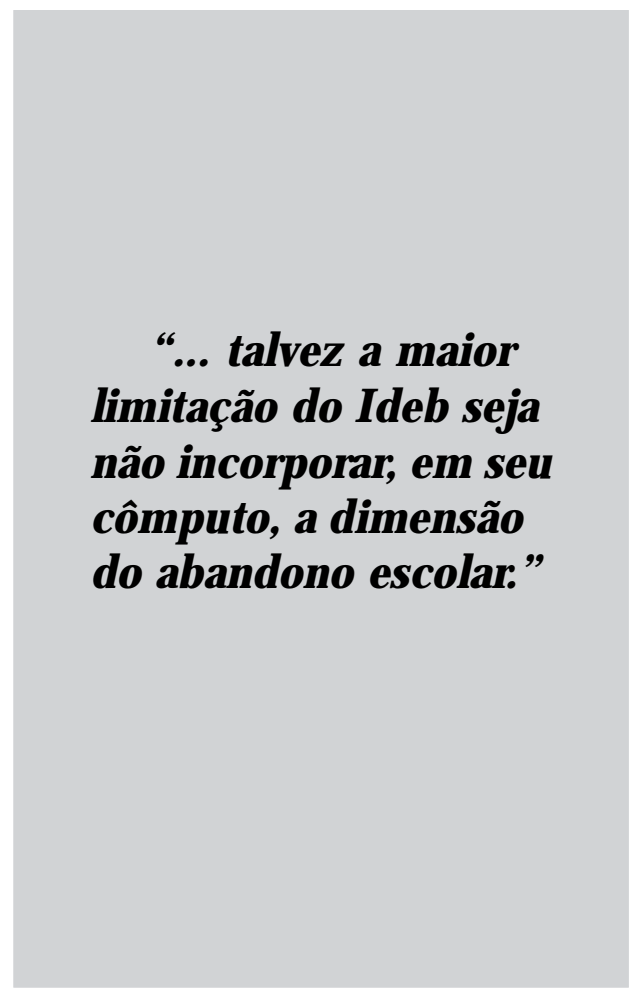

nota padronizada acaba assumindo um peso maior na definição do Ideb, como sugere 0 fato de ter um coeficiente de variação um pouco maior que a taxa de aprovação e uma correlação mais forte com o Ideb, como se pode verificar nos Gráficos 1a e 1b.

O utra limitação a ser apontada, acerca desse índice, não está relacionada à forma como foi definido, mas ao modo como 
está sendo usado. Como já foi mencionado, uma das ações do PDE é dar assistência, prioritariamente, a 1.242 municípios com os mais baixos Índices de D esenvolvimento da Educação Básica. Entende-se que o Ideb até pode ser usado como um dos critérios para a seleção de um determinado público, mas não como o único. Suponha que um município A, que está entre os priorizados, possua escolas com uma estrutura física razoável sob um certo padrão. Pressuponha agora que, fora dessas 1.242 localidades, exista outro município B com escolas em condições precárias de infra-estrutura. O ra, como 0 Ideb foi o fator preponderante de seleção, não contemplando a dimensão de infraestrutura, o município B continuará com uma infra-estrutura precária no que depender de apoio financeiro do MEC, ao menos momentaneamente, se 0 Ideb for 0 único indicador de priorização. Por ser um indicador essencialmente de resultados, pode ser considerado ainda válido para medir efeitos e impactos de ações e programas educacionais. Parece questionável, porém, a sua utilização como indicador para a priorização de públicos-alvo.

Mas talvez a maior limitação do Ideb seja não incorporar, em seu cômputo, a dimensão do abandono escolar. Embora considerado como um problema já solucionado em estados do Sul e Sudeste, 0 abandono ainda está presente em estados mais pobres. Enquanto que, por exemplo, a taxa de abandono para a primeira etapa do ensino fundamental da rede estadual de Santa Catarina situava-se abaixo de $1 \%$, no Piauí alcançava a cifra de $13,5 \%$ em 2005.

Fernandes (2007) justifica a ausência da dimensão "abandono escolar" no Ideb explicando que, por um lado, a presença de evasão durante a etapa de ensino ${ }^{2}$ elevaria a nota padronizada, uma vez que aqueles que abandonam tendem a possuir um desempenho inferior. Por outro, como o exame padronizado é geralmente aplicado antes de se determinar quem é, ou não, aprovado naquele ano, haveria uma subestimação da proficiência média, pois se estaria aplicando o exame para alunos que não serão concluintes daquela etapa de ensino, por terem sido reprovados. Na realidade, pelo fato de os exames serem aplicados entre o final de outubro e o começo de novembro, muitos daqueles que seriam reprovados talvez não mais freqüentassem as aulas, não prejudicando tanto assim a proficiência média. A hipótese apresentada por Fernandes (2007) é que esses vieses acabam compensando-se, garantindo que o Ideb, tal como computado, constitua uma boa medida.

A hipótese é interessante, mas há de se ponderar que, na sua forma atual, 0 Ideb não captaria situações em que os sistemas de ensino estivessem elevando os padrões de aprovação e mantendo a proficiência média, mas gerando também abandono dos alunos com dificuldades de aprendizado durante 0 ano letivo. Em tese, um gestor diligente com as metas do Ideb, mas mal intencionado em termos dos compromissos educacionais mais abrangentes do PDE, poderia até promover a dispensa de alunos com maiores dificuldades de aprendizado devido a problemas associados à pobreza, ao trabalho infantil etc., para garantir que não viessem a ser reprovados e/ ou obter um mau desempenho no exame de proficiência.

Entendendo a necessidade de se englobar a taxa de abandono no cômputo de um indicador sintético do PDE, apresenta-se na seção seguinte uma medida alternativa, o IDEB+. 


\section{Ideb+, uma proposta de aprimoramento do Ideb para considerar os efeitos da taxa de abandono}

É inquestionável a pertinência dos dois indicadores que compõem o Ideb, pois são capazes de sinalizar aos gestores educacionais a necessidade de garantir a progressividade dos alunos no sistema escolar segundo a idade esperada, sem prejuízo de que estes dominem os conhecimentos e habilidades requeridos. No entanto, como preconiza a quinta diretriz do Plano de Metas Compromisso Todos pela Educação, apresentado no Q uadro 2, os gestores de escolas nos municípios e estados devem também "combater a evasão pelo acompanhamento individual das razões da não-freqüência do educando ${ }^{3}$ e sua superação". Assim, considera-se fundamental que a dimensão "abandono" também seja abordada ao se avaliar o desenvolvimento da educação. Afinal, o abandono parece ser ainda mais prejudicial para 0 aluno, para sua família e para o País, do que a reprovação ou uma nota baixa em exames padronizados.

D essa forma, propõe-se um aprimoramento do Ideb, o Ideb+, com a incorporação de mais um indicador de rendimento, a Taxa de Permanência (M), medida complementar da taxa de abandono, na fórmula original da medida (5).

$$
\begin{aligned}
& \mathrm{IDEB}_{\mathrm{ji}}=\mathrm{N}_{\mathrm{ji}} \mathrm{x} \mathrm{P}_{\mathrm{ji}} \mathrm{x} \mathrm{M}_{\mathrm{ji}} \\
& \text { Com } \\
& \mathrm{M}=100 \cdot \frac{\text { A fasts }}{\text { Ms-AFs +ADs + RECs-DESs }}
\end{aligned}
$$

Onde: $s=$ série do ensino fundamental ou ensino médio.

$\mathrm{A}$ fast $=$ número de afastados por abandono na série ou grupo de séries s;

Ms = matrícula inicial na série ou grupo de séries $s_{;}$

A F $s$ a a astados por abandono ou transferência na série ou grupo de séries s;

A D $s=$ admitidos por transferência na série ou grupo de séries $\mathrm{s}$;

RE C $s=$ Reclassificados para a série ou grupo de séries s;

D E Ss = alunos que saíram da série ou grupo de séries s, por reclassificação.

Vale observar que o uso da Taxa de Permanência, tal como definida acima no cômputo do Ideb+, é uma opção metodológica pragmática para inserir o grau de atendimento escolar nos municípios ou nas áreas de abrangência das escolas. Ao se adotar as fórmulas - (5) e (6) - o que se acompanha no Ideb+ é o abandono de alunos já integrados ao sistema escolar, e não a falta de atendimento ou a não freqüência escolar de crianças em uma dada região ou localidade. Para tanto, idealmente, a cobertura e o esforço da universalização do ensino deveriam ser medidos pela taxa de atendimento escolar ou taxa de escolarização líquida. Contudo, como apresentado em Inep (2004), essas medidas requerem, no denominador, estimativas de público-alvo nas idades normativas para os níveis de ensino, algo extremamente complexo para se computar em nível de escola para áreas de abrangência das mesmas se for desejável que o Ideb+, tal como o indicador original, seja calculado para esse nível de detalhamento de unidade de prestação de serviço. Certamente que, em nível municipal, é possível dispor dessas estimativas, mas a precisão delas tende a piorar quanto mais distantes estão dos censos demográficos ${ }^{4}$. 
Assim, em detrimento da validade do Ideb + de captar, de fato, o grau de atendimento escolar, mas procurando preservar sua desagregabilidade em nível de escolas e garantir maior confiabilidade (de modo a não carregar possíveis erros sistemáticos de medida, decorrentes das estimativas menos precisas de população em idade escolarno período intercensitário), optou-se por usar a taxa de permanência definida em $(6)^{5}$. Como observado anteriormente, nem sempre é possível garantir todas as propriedades desejáveis para 0 indicador construído. Em situações concretas, talvez mais valha dispor de um indicador imperfeito com bom grau de confiabilidade e comparabilidade no tempo e no território do que um supostamente perfeito, com maior validade de constructo, mas com problemas de mensuração, cujo dimensionamento nem se sabe precisar.

Um dos aspectos interessantes do Ideb+ é que, tendo preservado o modelo multiplicativo na sua construção, 0 aumento ou a diminuição do indicador pode ser interpretado a partir da variação relativa dos seus componentes (9), assim como no Ideb original.

(9) $\frac{\triangle \mathrm{IDEB}}{\mathrm{IDEB}}=\frac{\triangle \text { Nota }}{\text { Nota }}+\frac{\triangle \mathrm{Tx} \text { Aprov }}{\text { Tx Aprov }}+\frac{\triangle \mathrm{Tx} \text { Perm }}{\text { Tx Perm }}$
O cômputo do Ideb+ de 1999 a 2005 revela que, embora seja menor que 0 Ideb original, já que $\mathrm{M}<100 \%$, ele aponta uma evolução mais positiva para o ensino fundamental no período - Tabela 4 e Gráficos 2a e 2b. Enquanto o aumento do Ideb entre 1999 e 2005 foi de 5,9\%, a do Ideb+ foi de $11,2 \%$, como conseqüência do aumento de 5,0 pontos percentuais da taxa de permanência, além do aumento da taxa de aprovação de 4,6 pp no período, o que afetou os dois indicadores indistintamente. Isso mostra a importância da inclusão do abandono escolar como mais uma dimensão a ser avaliada. Assim, com base no Ideb+, poderia-se dizer que houve uma melhora significativa da educação básica nas primeiras séries do ensino fundamental, como resultado do aumento da taxa de permanência e da taxa de aprovação e, de maneira tímida, do aumento do desempenho dos alunos no Saeb.

Como era de se esperar, assim como a medida original, o Ideb+ está fortemente correlacionado com seus indicadores componentes. Também no Ideb+a correlação mais intensa é com a nota padronizada $(0,85)$, seguida da taxa de aprovação $(0,78)$ e, por fim, a taxa de permanência $(0,74)$ - Gráfico 3 .

Tabela 4: Evolução do Ideb+ e seus componentes Brasil - Rede Estadual - Anos iniciais do ensino fundamental - 1999 a 2005.

\begin{tabular}{|c|c|c|c|c|c|c|}
\hline Ano & $\begin{array}{c}\mathrm{P}=\mathrm{Tx} \text {. mxidia de } \\
\text { aptivaçẫo } \%\end{array}$ & $\begin{array}{l}\text { Métía da } \\
\text { nuta } \\
\text { padtrnnizada }\end{array}$ & $\begin{array}{c}\text { Ideb }=N \\
\times P\end{array}$ & $\begin{array}{c}\text { Taxa méslia } \\
\text { de ahandneu } \\
\%\end{array}$ & $\begin{array}{c}\text { M= Tava médfia } \\
\text { de permuanêneia } \\
\%\end{array}$ & $\begin{array}{l}\text { Ideb+ }= \\
\text { NxP PxM }\end{array}$ \\
\hline 1999 & 78,800 & 4,56 & 1,55 & 10,20 & प्र9, & 3,19 \\
\hline 2001 & 79,70 & 4,33 & 3,45 & 8,20 & 91,8 & 3,17 \\
\hline 2013 & $+00,80$ & 4,42 & 3,57 & 6,60 & 93,4 & 3,34 \\
\hline 20105 & H1, 60 & 4,61 & 3,76 & 3,70 & 94,3 & 3,53 \\
\hline Vas. 19992005 & 4,62 & 1,27 & 5,94 & 4,12 & $5,0 t$ & 11,25 \\
\hline
\end{tabular}

Fonte: Elaboração própria com informações de Inep (2007a) e Edudata Brasil. 
Mesmo considerando que o Ideb+ represente melhor a agenda de programas e ações do PDE, o fato é que ele compartilha das limitações apontadas anteriormente para o Ideb. Além disso, as duas medidas só podem oferecer uma visão geral e sumária dos resultados e impactos das 28 iniciativas do Plano de Metas Compromisso Todos pela Educação. Para se obter uma visão mais completa e importante do PDE, e poder acompanhar seus programas, é preciso dispor não apenas de um indicadorsíntese, mas de um painel de indicadores de monitoramento e avaliação, que retratem dimensões de como os insumos da política se processam em resultados e impactos, isto é, de como os programasmeio e iniciativas de natureza políticoorganizacional ou didático-pedagógica estão se desenvolvendo e, eventualmente, produzindo efeitos de médio alcance, captáveis por indicadores de processos. É o que se procura ilustrar a seguir.

Gráfico 2: Evolução do Ideb e Ideb+ e seus componentes segundo níveis de ensino - Brasil - Rede Estadual - 1999 a 2005.
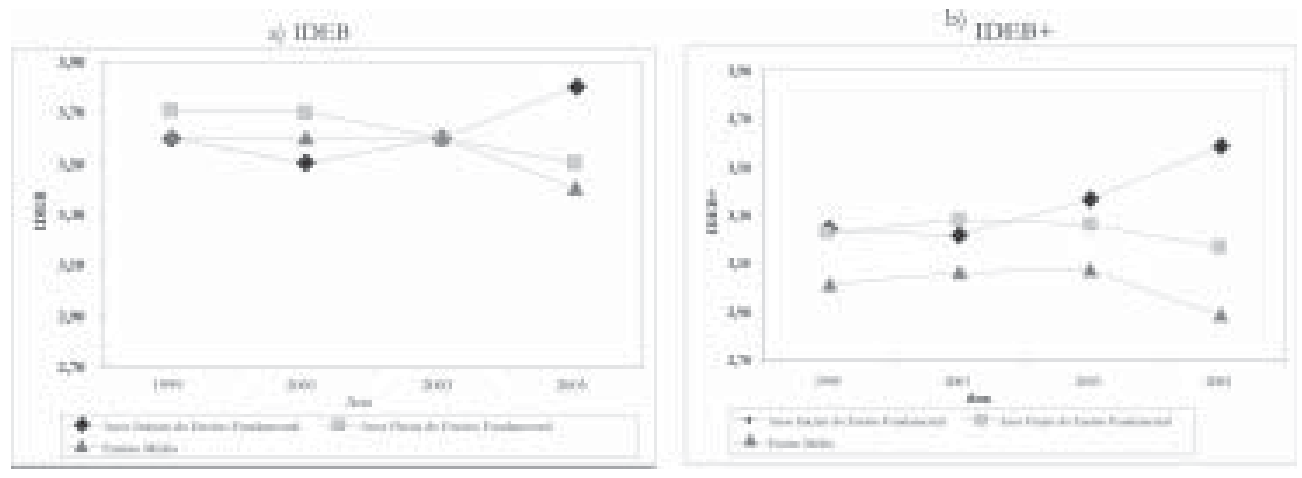

\section{Gráfico 3: Comelação entre o Ideb+ e seus componentes}

\section{Brasil - Rede Estadual - Anos iniciais do ensino fundamental 2005.}
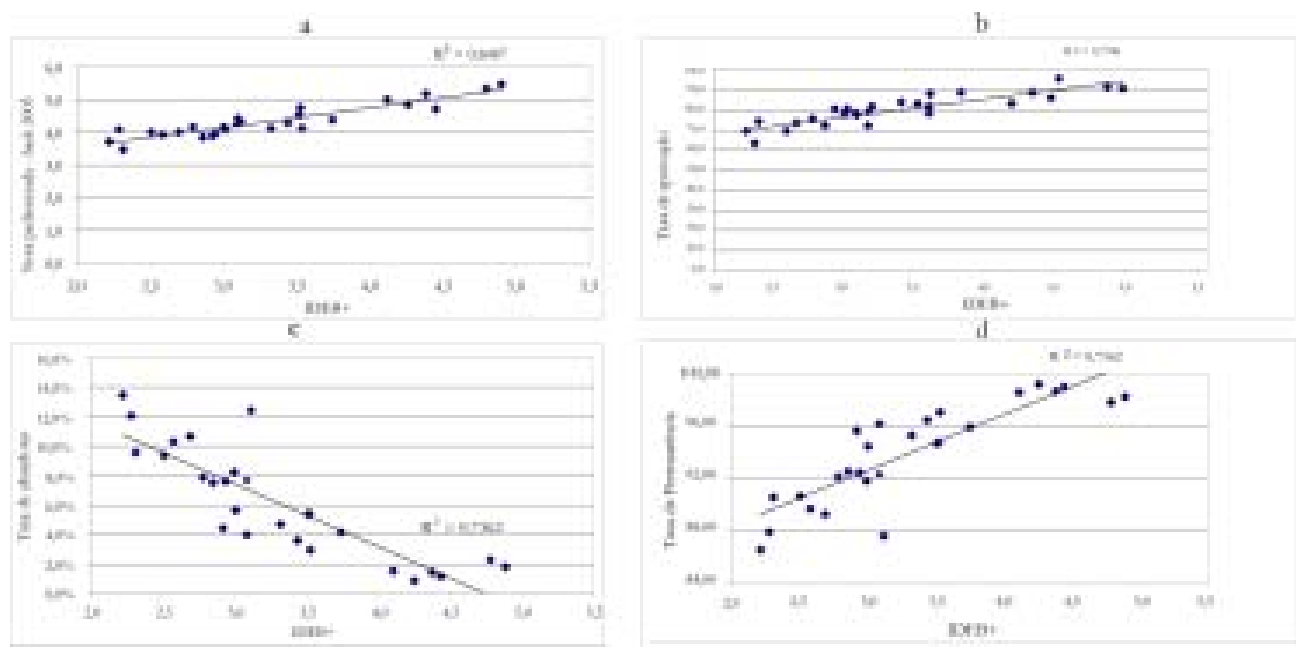
Para além de um indicadorsíntese, um Painel de Indicadores de Monitoramento do

\section{Desenvolvimento da Educação Básica - Pideb+}

Como o PDE abrange uma série de programas, que vão da educação infantil à educação superior, seu monitoramento não pode ser realizado apenas com base em um indicador. Monitorar ou avaliar o estágio de "desenvolvimento da educação" requer indicadores de outras dimensões da educação, como indicadores de oferta, de atendimento, de acesso e participação, de eficiência, de rendimento e até mesmo de financiamento.

Para atender a essa necessidade, propõe-se, nesta seção do trabalho, a construção de um Painel de Indicadores de Monitoramento do Desenvolvimento da Educação Básica - (Pideb+), como demonstrado no Quadro 3. Optou-se por não propor um sistema exaustivo de indicadores, mas um conjunto reduzido de medidas de acompanhamento, que permitisse monitorar as ações mais importantes nas distintas fases do ciclo de implementação dos programas. Ou seja, 0 Painel de Indicadores é uma proposta intermediária entre o "caos informacional" de um sistema exaustivo de medidas de acompanhamento e a "pobreza informacional" trazida por apenas uma medidasíntese. A idéia é que o Painel seja uma proposta mais efetiva de monitoramento ao priorizar as dimensões de importância gerencial ao gestor, para quem foi idealizado. No caso em questão, o painel proposto tem como foco os gestores federais, mais especificamente os do Ministério da Educação. Naturalmente, esse painel deve ser ajustado às necessidades de acompanhamento para outros gestores, de acordo com o escopo de sua função e de seu papel dentro do conjunto de ações e programas do PDE.

Para a construção do Pideb+ foram utilizados indicadores com características como inteligibilidade, validade, relevância, confiabilidade, sensibilidade, desagregabilidade e, também, historicidade. As informações utilizadas foram basicamente as do censo escolar, disponibilizadas anualmente pelo Inep, e outras disponibilizadas pelo IBGE. É desejável que se possa dispor de alguns indicadores em base semestral (abandono, por exemplo), trimestral (professores capacitados) ou, até mesmo, mensal (como recursos financeiros alocados ou transferidos). Para isso, será necessário desenvolver rotinas de coleta de dados primários ou, em alguns casos, disponibilizar informações de controle já existentes em departamentos e programas.

Foi realizada uma seleção de um conjunto manejável de indicadores, referidos aos compromissos e ações do PDE - para a educação básica e, em especial, para 0 ensino fundamental - segundo uma lógica de insumo, processo, resultado e impacto. Na dimensão insumo deu-se prioridade aos indicadores voltados para o financiamento da educação, já que no PDE é mencionado 0 apoio financeiro, além do técnico, do Governo Federal aos estados e municípios que assinarem o termo do Compromisso. Além disso, o PDE prevê o aumento de recursos do $\mathrm{PDDE}^{6}$ para as escolas que cumprirem as metas do Ideb.

Para a dimensão "processo" foram definidos indicadores que pudessem ser produzidos com certa regularidade e que estivessem relacionados ao processo de ensino-aprendizagem, principalmente na figura do professor. Justifica-se o uso de indicadores com foco nos docentes por causa da preocupação do PDE com 
questões como a formação continuada de professores, implementação de planos de carreira e piso salarial dos profissionais do magistério. A inclusão de indicadores de acesso de alunos a laboratórios de informática se justifica pela necessidade de monitorar uma ação, presente no PDE, de instalar um laboratório de informática em todas as escolas públicas do Brasil.
Para a escolha dos indicadores de resultado foram selecionados indicadores mencionados no PDE, assim como outros discutidos anteriormente, como a taxa de abandono e o Ideb+. Já os indicadores de impacto devem ser entendidos como alguns dos exemplos dos impactos que a educação tem na vida dos estudantes a médio e longo prazos. Vale ressaltar que

\section{Quadro 3: Painel de indicadores sugeridos para Monitoramento do Desenvolvimento da Educação Básica, definidos para gestores do MEC}

\begin{tabular}{|c|c|c|c|}
\hline Dimenงลีด & Indicador & $\begin{array}{l}\text { Desiagregacio } \\
\text { Geografica }\end{array}$ & Periodicidade \\
\hline & 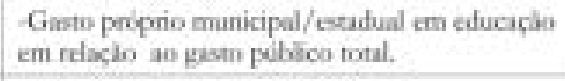 & Estados e Municipios & Anual \\
\hline Insumo & $\begin{array}{l}\text { Gasto tatal irsluindo o Furaleb* } \\
\text { Gasto matio por aluno } \\
\text { Gasto por aluno com rccursos do PDDE }\end{array}$ & $\begin{array}{l}\text {-Estados o Municipios } \\
\text {-Estados e Munichios } \\
\text { - Estados, Muricipios e } \\
\text { escola }\end{array}$ & $\begin{array}{l}- \text { Amual } \\
- \text { Anual } \\
- \text { Amual }\end{array}$ \\
\hline Proceseo & 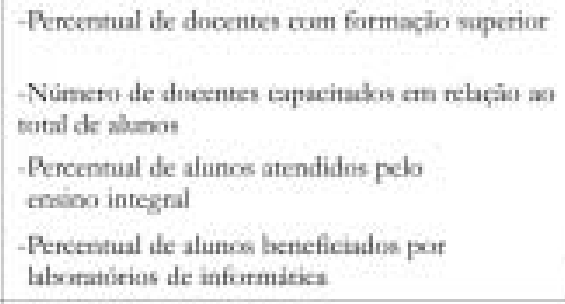 & 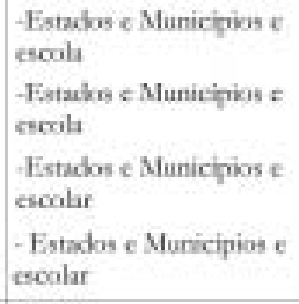 & $\begin{array}{l}- \text { Anual } \\
- \text { Anual } \\
\text {-Anual } \\
\text { - Anual }\end{array}$ \\
\hline Resultado & 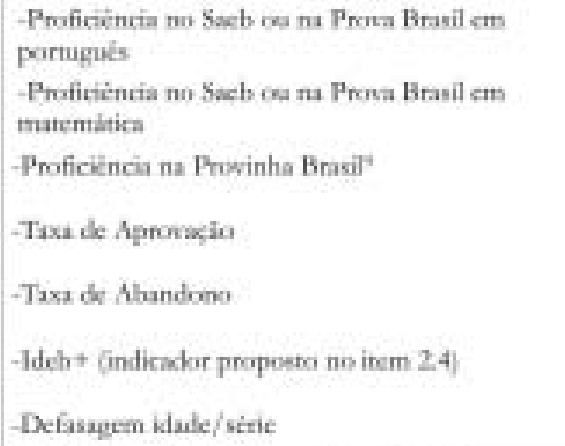 & 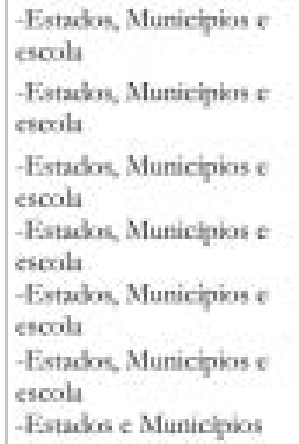 & $\begin{array}{l}\text { - Hamal } \\
\text { - Anarnal } \\
\text {-Anual } \\
\text { - Anual } \\
\text { - Manual } \\
\text {-Anual }\end{array}$ \\
\hline Impacto'15 & 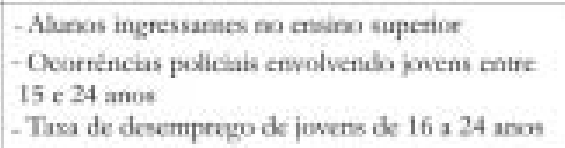 & $\begin{array}{l}\text { Estadual e munirapal } \\
\text { Estadual } \\
\text { Estadual }\end{array}$ & $\begin{array}{l}\text { Anual } \\
\text { Amual } \\
\text { Anual }\end{array}$ \\
\hline
\end{tabular}


estes não dependem exclusivamente das ações, programas ou projetos do PDE, mas também de outras ações governamentais, como programas de transferência de renda, investimentos em infra-estrutura urbana, crescimento econômico e do emprego etc.

$\mathrm{Na}$ Figura 3, descreve-se um dos possíveis formatos de apresentação e de organização dos indicadores do PIdeb+, passível de implementação em softwares específicos de D ataW arehouse e aplicativos mais simples, como o Monit ${ }^{7}$.

\section{Considerações finais}

A criação do Índice de Desenvolvimento da Educação Básica (Ideb) para avaliar as ações do PDE constitui, certamente, uma proposta inovadora, vindo ao encontro de uma tendência no setor público de utilização de indicadores para auxílio de gestores na tomada de decisões. Os indicadores auxiliam a tomada de decisões nas diversas fases do ciclo das políticas públicas, assim como asseguram, em muitos casos, maior transparência e acountability das ações do governo.

O Ideb foi construído com uma metodologia consistente que usa duas dimensões semelhantes, compostas por indicadores de resultado que se afetam mutuamente em sentidos opostos. Esse índice é de alta relevância para o PDE por ser constituído por dimensões que integram o foco do Plano, ou seja, a qualidade da educação básica. Sua escala de mensuração é de fácil compreensão não somente para os gestores, como para toda a população. Por ser elaborado no Brasil, esse instrumento se adéqua à realidade nacional, contemplando as dimensões consideradas relevantes para o desenvolvimento da educação. 0 Ideb goza tanto de forte legitimidade política, devido aos decretos que o colocam na agenda formal de governo, quanto de legitimidade técnica a partir das características metodológicas de sua construção e fontes de dados usadas.

Como todo indicador, o Ideb também possui limitações, como a perda de referência provocada pela padronização das notas dos exames padronizados e a baixa especificidade para programas de determinadas áreas, como Português ou Matemática.Também deixa de considerar, em seu cômputo, uma relevante dimensão: 0 abandono escolar.

A alternativa apresentada neste estudo, que considera a dimensão do abandono escolar, mantendo o modelo multiplicativo (Ideb+), parece configurar uma proposta promissora, ao revelar, pela série histórica, os efeitos da redução do abandono como uma das dimensões importantes do desenvolvimento educacional nos últimos 10 anos. D evido à multiplicidade de programas e ações do PDE, a proposta de painel de indicadores que considere as dimensões mais relevantes e convergentes de seus programas e ações é certamente a alternativa mais consistente para 0 monitoramento e avaliação do Plano.

Há muito por fazer para que 0 PDE possa produzir os efeitos esperados na melhoria da qualidade da educação no Brasil. A proposta de indicadores aqui apresentada é uma modesta contribuição para que os técnicos e gestores encarregados dos programas possam desenvolver seus sistemas de acompanhamento, indicadores de monitoramento e medidas de desempenho organizacional que assegurem maior objetividade, transparência e efetividade às suas ações.

(Artigo recebido em de junho de 2008. Versão final em de julho de 2008). 
Figura 3: Ilustração de um Painel de Indicadores de Monitoramento do PDE

Painel de Monitoramento do Plano de Desenvolvimento da Educação
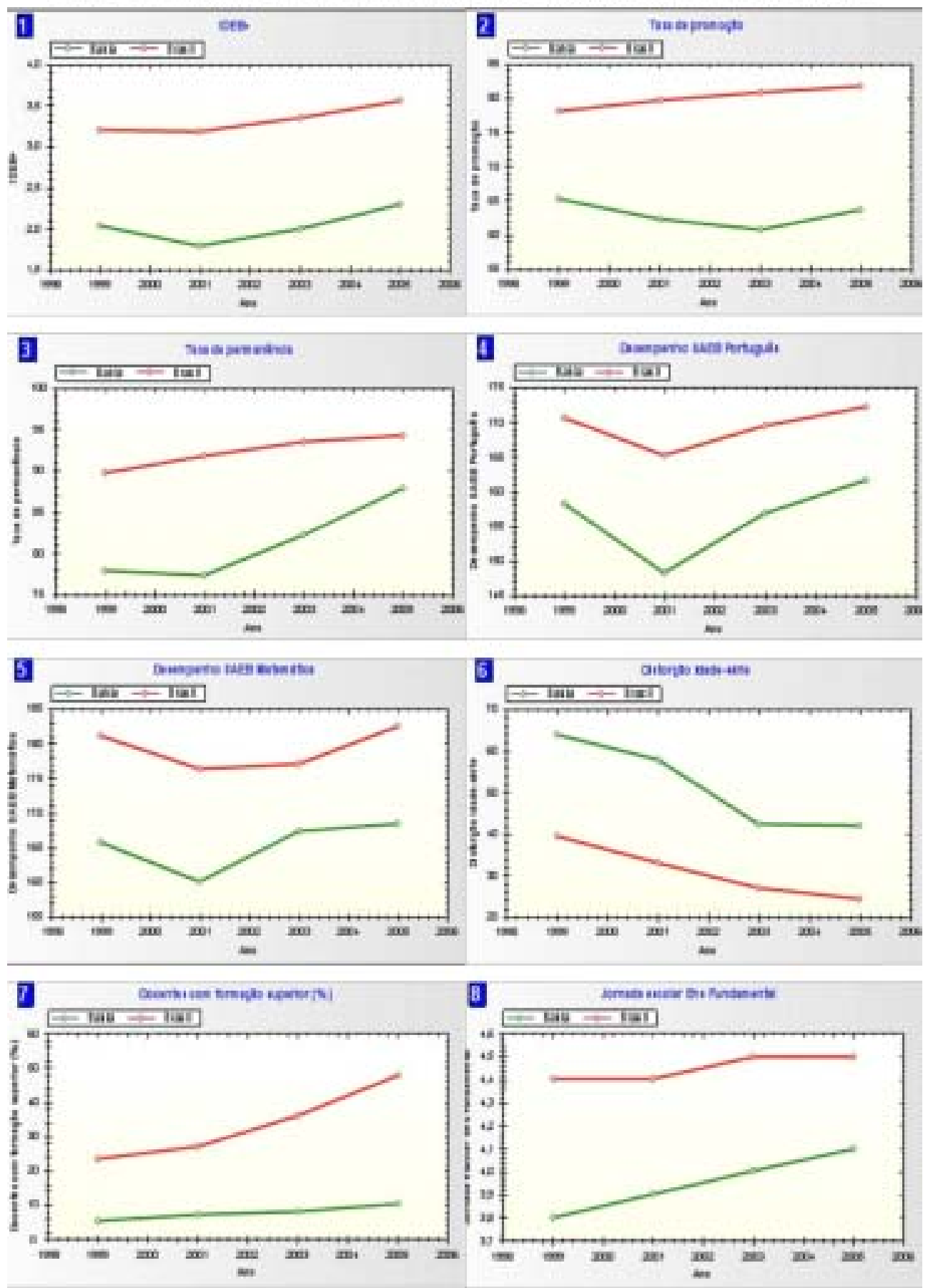


\section{Notas}

* Este texto corresponde a uma extração revisada da monografia “Índice de D esenvolvimento da Educação Básica - ID EB: usos, limitações e alternativas”, apresentada ao Curso de E specialização em Políticas Públicas da Educação com Ênfase em Monitoramento e Avaliação - MPA, em fevereiro de2008 (Rezende, 2008).

${ }^{1}$ Tribunal D E Contas D A União. Relatório de avaliação deprogramas: Ação Apoio à Formação Continuada de Professores do Ensino Fundamental. Brasília: TCU, 2006.

${ }^{2}$ A expressão "evasão durante a etapa" deve ser entendida como abandono, pois para o D icionário de Indicadores Educacionais (MEC/ INEP, 2004) a evasão é quando um aluno, antes matriculado em um determinado ano, não aparece nas matrículas do ano seguinte; já o abandono ocorre durante um mesmo ano letivo (etapa de ensino).

${ }^{3}$ Note-se que a não freqüência do educando está mais relacionada a abandono do que à evasão escolar.

${ }^{4}$ O IBGE não disponibiliza ainda estimativas de população por faixas etárias ou em idade escolar em nível municipal para os anos intercensitários, mas somente os totais populacionais. 0 D atasus (www.datasus.gov.br) dispõe de informações populacionais dessa natureza, mas há problemas de precisão para anos afastados do censo demográfico.

${ }^{5}$ Tal como definido, a taxa de permanência poderia ser a soma da taxa de aprovação e da taxa de repetência. Assim, quanto menor for a variabilidade das taxas de evasão escolar, por construção, maior a correlação entre a taxa de permanência e suas duas parcelas.

${ }^{6}$ Programa D inheiro Direto na Escola do MEC/ FNDE.

${ }^{7}$ Aplicativo desenvolvido como plataforma de disseminação dos resultados do Projeto de Indicadores de Direitos Humanos, ENCE/ IBGE, 2008.

${ }^{8}$ Fundo de Manutenção e D esenvolvimento daE ducação Básica e deValorização dos Profissionais da Educação.

${ }^{9}$ Avaliação de alfabetização que avaliará alunos de seis a oito anos de idade.

${ }^{10} \mathrm{~A}$ credita-se que são inúmeros os impactos que podem ser produzidos pelo PDE, no entanto, selecionamos apenas algumas dimensões mensuráveis periodicamente.

\section{Referências bibliográficas}

BRAsil. Decreto $\mathrm{n}^{0}$ 6.094, de 24 de abril de 2007. D ispõe sobre a implementação do Plano de Metas Compromisso Todos pela Educação, pela União Federal, em regime de colaboração com Municípios, Distrito Federal e Estados, e a participação das famílias e da comunidade, mediante programas e ações de assistência técnica e financeira, visando à mobilização social pela melhoria da qualidade da educação básica. Diário Oficial da União de 25 abr. 2007.

Cohen, Ernesto; Franco, Rolando. A valiação de projetos sociais. Petrópolis, RJ: Vozes, 1999. 
CunHA, José et al. Proposta metodológica de elaboração de indicador educacional sintético para os municípios. Revista Brasileira de E studos de População, [S. l.: s. n.] v.18, n 1/ 2, p. 131-159, jan./ dez. 2001.

Fernandes, Reynaldo. Índice de Desenvolvimento da Educação Básica (Ideb). Série D ocumental. Tex tos para D iscussão. Brasília, n 26: Inep, 2007.

G uimarães, José \& Jannuzzi, Paulo. IDH, Indicadores sintéticos e suas aplicações em políticas públicas: uma análise crítica. Revista Brasileira. E st. U rbanos e Regionais, Salvador 7 (1): p. 73-89, 2005.

Instituto Nacional D e Estudos e Pesquisas Educacionais Anísio Teixeira. D icionário de indicadores educacionais: fórmulas de cálculo. Brasília: [s. n.], 2004.

Consulta ao Índiœ de D esenvolvimento da E ducação Básica - ID E B. 2007.

Disponível em: http:/ / ideb.inep.gov.br/ Site/ . Acesso em 4 de fev. 2007.

. N ota técnica. Índice de D esenvolvimento da Educação Básica. [ca. 2007].

Disponível em: http:/ / ideb.inep.gov.br/ Files/ Site/ D ownload/ Nota_Tecnica IDEB.pdf. Acesso em 4 de fev. 2007.

Jannuzzi, Paulo. Considerações sobre o uso, mau uso e abuso dos indicadores sociais na formulação e avaliação de políticas públicas municipais. R evista deA dministração Pública, Rio de Janeiro 36 (1): p. 51-72. Jan/ Fev. 2002.

. Indicadores sociais no Brasil: conœitos, fonte de dados e aplicaôoes. Campinas: Alínea,

2004.

. Indicadores para diagnóstico, monitoramento e avaliação de programas sociais no Brasil. Revista do Servico Públic, Brasília 56 (2): p. 137-160. Abr./ Jun. 2005.

Ministério D A E duCAÇÃo. 0 plano de desenvolvimento da educação, razões, prinćpios eprogramas. [S. l. : s. n.], [2007?]. [D ownload de: http:/ / portal.mec.gov.br/ arquivos/ pdf/ livromiolov4.pdf] Acesso em: 25 Nov 2007.

Nascimento, Beatrice. A reforma universitária de 1968: origem, processo e resultados de uma política para o ensino superior. Tese de D outorado, UFRJ, 1991.

O TTONI, Cristiano. Indicadores sociais na formulação de políticas públicas federais brasileiras: teoria e prática. Brasília, UnB, 2006 (Dissertação de Mestrado em Gestão Social e Trabalho).

Rezende, Leonardo. Índiœ de D esenvolvimento da E ducação Básica - ID E B: usos, limitaơões e alternativas. Brasilia, ENAP, 2008 (Monografia apresentada ao Curso de Especialização em Políticas Públicas da E ducação com Ênfase em Monitoramento e Avaliação - MPA, para servidores do Ministério da Educação).

RuA, Maria. A avaliação no ciclo da gestão pública. Apostila do curso de Especialização em Políticas Públicas da Educação com Ênfase em Monitoramento e Avaliação - MPA. ENAP. MIMEO, 2004.

Scandar Neto, Wadih et al. Sistemas de indicadores ou indicadores sintéticos : do que precisam os gestores de programas sociais In: HENRIQUES,R. et al (O rg). E ducacão na diversidade : como indicar as diferenças? (Coleção Educação para Todos, Série Avaliação). Brasília, MEC/ Unesco, n. 8, v. 25, p. 16-34. 2006.

Síntese que organiza o olhar: uma proposta para construção e representação de indicadores de desenvolvimento sustentável e sua aplicação para os municípios fluminenses. ENCE/ 
IBGE, Rio de Janeiro, 2006. (D issertação de Mestrado em Estudos Populacionais e Pesquisas Sociais).

Tribunal D e Contas D A União. Relatório de avaliação de programas: A ção A poio à Formação Continuada de Professores do E nsino Fundamental. Brasília: TCU, 2006. 


\section{Resumo - Resumen - Abstract}

\section{Monitoramento do Plano de Desenvolvimento da Educação: proposta de aprimora- mento do Ideb e de painel de indicadores}

L eonardo Milhomem de Rezendee Paulo de Martino Jannuzzi

Nas últimas duas décadas, tem-se observado um processo cada vez mais intenso de proposição de indicadores de monitoramento e avaliação da ação governamental, assim como de indicadores sociais gerais, dentro e fora das organizações públicas. No campo das políticas educacionais, especificamente, sob os auspícios do Plano de D esenvolvimento da Educação (PDE), propôs-se mais uma dessas medidas, o Índice de D esenvolvimento da Educação Básica (Ideb). 0 objetivo deste trabalho é analisar seus usos, características e limitações, além de propor medidas alternativas e complementares para acompanhar os resultados e impactos do PD E. O texto está organizado em cinco seções. Na primeira seção discute-se o papel e o uso dos indicadores no ciclo de políticas públicas, em especial no monitoramento e avaliação de programas. A seção seguinte tem caráter mais metodológico, tratando da construção de indicadores sintéticos, seus usos e limitações. A presentase, então, o Ideb e se discute suas características, potencialidades e restrições para acompanhamento da agenda da política educacional. As duas últimas seções são dedicadas à apresentação de uma proposta de indicador alternativo - o Ideb + e o Painel PIdeb + - para monitoramento do PDE.

Palavras-chave: Indicadores educacionais, Ideb, Plano de D esenvolvimento da E ducação.

\section{Monitorización del Plan de D esarrollo de la Educación: propuesta de perfeccionamiento del Ideb y el panel de indicadores}

L eonardo Milhomen de Rezende y Paulo de Martino Jannuzzi

En las dos últimas décadas se ha observado un proceso, cada vez más intenso, de proposición de indicadores de monitorización y evaluación de la acción gubernamental, y también de indicadores sociales generales que hay en las organizaciones públicas e fuera de ellas. En el campo delas políticas educacionales, específicamente bajo los auspicios del Plan de D esarrollo de la Educación (PD E), se ha propuesto una más de estas medidas: el Índice de D esarrollo de la Educación Básica (Ideb). El objeto de este trabajo es hacer el análisis de sus características, usosy limitaciones; incluso proponer medidas alternativas y complementarias para seguir los resultados y los impactos del PDE. El texto está compaginado en cinco secciones. En la primera de ellas, se discuten el papel y los usos de indicadores en el ciclo de políticas públicas, especialmente la monitorización y evaluación de programas. La sección siguiente tiene un carácter metodológico al tratar de la construcción de indicadores sintéticos, sus usos y limitaciones. Entonces, se presenta el Ideb y se discute sus características, potencialidades y restricciones para seguir la agenda de política educacional. Las dos últimas secciones se dedican a la presentación de una propuesta de indicador alternativo ( Ideb+) y el panel (PID EB+) para monitorización del PDE.

Palabras clave: Indicadores Educacionales, Ideb, Plan de D esarrollo dela E ducación

\section{Monitoring the National Educational Plan: a proposal to improve Ideb and the panel of indicators}

L eonardo M ilhomem de Rezendeand Paulo de M artino Jannuzzi

In the last two decades there has been a growing interest on monitoring and evaluation indicators of governmental programs and also on broad social indicators, in and outside public agencies. On educational matters, more precisely, moved by the National Education Plan (PDE), it has been 
proposed the Ideb - Indicator of basic Education D evelopment. This paper aims to analyze its main aspects, its uses and limitations and also propose other different measures to follow up the PDE's results and impacts. The paper is divided in five sections. In the first section it is discussed the role and application of indicators in the policy cycle, more precisely on program monitoring and evaluation. The next section is concerned on methodological matters of building composite indicators, its uses and weakness. Then, Ideb is presented and discussed as a tool to follow up the educational agenda. The last sections are dedicated to the presentation of Ideb+ and PIdeb+ panel, different indicators that can be used to evaluate PDE.

Key words: Educational Indicators, Ideb, National Education Plan.

Leonardo Milhomem de Rezende

Servidor do Ministério da Educação, Especialista em Políticas Públicas da Educação com Ênfase em Monitoramento e Avaliação pela ENAP.

Contato: leonardo.rezende@mec.gov.br

Paulo de Martino Jannuzzi

Professor da Escola Nacional de Ciências Estatísticas do IBGE e colaborador da Escola Nacional de Administração Pública e PUC- Campinas. Pesquisador do CNPq no Projeto "Informação estatística no ciclo de formulação, monitoramento e avaliação de políticas públicas no Brasil” (Proc. 307101/2004-5).

Contato: paulo.jannuzzi@ibge.gov.br 